\title{
Tycho, Longomontanus, and Kepler on Ptolemy's Solar Observations and Theory, Precession of the Equinoxes, and Obliquity of the Ecliptic
}

N.M. Swerdlow

\begin{abstract}
It therefore remains that either Ptolemy committed fraud with fabricated observations, or from a kind of awe and reverence for the ancients preferred to confirm rather than refute them, neither of which is likely in the philosopher Ptolemy, a defender of candor and truth, as is witnessed by many judgments, especially since he could expect no advantage or fame from this, but rather greater advantage and fame from correcting the ancients. But that he was not obsequious to the ancients, he left witnessed in many. ways, refuting Hippanchus where it was required.
\end{abstract}

Johannes Kepler (1937-, 21.1.324).

It is well known that there are errors in Ptolemy's observations of the Sun with consequences for his own astronomy and for later astronomy up to some time in the seventeenth century. The principal problems and their consequences in Ptolemy's astronomy are the following:

(1) The latitude of Alexandria is taken to be $\varphi=30 ; 58^{\circ}$ when correctly it is $31 ; 13^{\circ}$, an error of $-0 ; 15^{\circ}$. In Almagest 2.5 Ptolemy describes, although does not recommend, a method of finding the latitude from the length of the Sun's shadow at both solstices or a solstice and equinox, which would make the latitude an error in measurement of the Sun's zenith distance. Indeed, for $\varphi=30 ; 58^{\circ}$, $\tan \varphi=0 ; 36,0=3 / 5$, so that where the length of a gnomon is 60 , in the equator the length of the shadow is 36 , which does suggest use of or adjustment to a rounded shadow length. The consequence is that the meridian altitude of the celestial equator is too high, or its zenith distance too low, by $0 ; 15^{\circ}$, about 15 hours in the motion of the Sun in declination and $0 ; 37^{\circ}$ in longitude near the

N.M. Swerdlow

Humanities and Social Sciences, California Institute of Technology, Pasadena, CA, USA c-mail: swerdlow @ caltech.edu 
equinoxes, and the error of $0 ; 15^{\circ}$ in meridian altitude and zenith distance affects the entire ecliptic.

(2) The obliquity of the ecliptic is taken to be $\varepsilon=23 ; 51,20^{\circ}$ when by modern computation in 140 it was $23 ; 40,39^{\circ}$ an error of nearly $+0 ; 11^{\circ}$. From measurements of the zenith distance of the Sun at summer and winter solstice, Ptolemy found the arc between the tropics $2 \varepsilon$ to lie between $47 \frac{2}{3}^{\circ}$ and $47 \frac{3}{4}^{\circ}$, and converted the lower limit to a ratio by $47 \frac{2}{3} / 360=143 / 1080=(11 \cdot 13) / 1080=11 / 83 \frac{1}{3} \approx$ $11 / 83$, that is, the arc between the tropics is about 11 (parts) of which the meridian is 83 . He notes that he derives nearly the same ratio as Eratosthenes, which Hipparchus also retained, a cryptic remark that has provoked a great deal of fanciful speculation. The derivation given here is by Delambre; although he attributes it to Eratosthenes rather than Ptolemy, which is scarcely possible. Before considering any other explanation of the ratio, it is first necessary to show that Delambre's is not correct. In any case, $2 \varepsilon=11 / 83 \cdot 360^{\circ} \approx 47 ; 42,40^{\circ}$ and $\varepsilon=23 ; 51,20^{\circ}$.

3) The dates of Ptolemy's observations of three equinoxes and one summer solstice are from about 21 to 36 hours late. The consequences are to confirm exactly Hipparchus's length of the tropical years, $365 \frac{1}{4}-\frac{1}{300}$ days $=365 ; 14,48^{\mathrm{d}}=$ $365^{\mathrm{d}} 5 ; 55,12^{\mathrm{h}}$, too long by $+0 ; 6,26^{\mathrm{h}}$, and to establish an epoch of the mean longitude of the Sun too low by $-1 ; 5^{\circ}$ in 132 , which indirectly affects the longitudes of the Moon, planets, and fixed stars. Because of the error in the length of the year, the error in the times of equinoxes accumulates at the rate of $+10 ; 43^{\text {h }}$ per century and the error in the mean longitude of the Sun at $-0 ; 26,25^{\circ}$ per century, and this too affects the longitudes of the Moon, planets, and fixed stars. The equinoxes and solstices cited by Ptolemy with specific dates and times are compared with modern computation in the Appendix and cited here by number.

1) Ptolemy uses the same intervals as Hipparchus between the equinoxes and summer solstice, to one-half day, and derives the same eccentricity and direction of the apsidal line. Thus, from the vernal equinox to summer solstice $94 \frac{1}{2}^{\mathrm{d}}$, summer solstice to autumnal equinox $92 \frac{1}{2}^{\mathrm{d}}$, vernal to autumnal equinox $187^{\mathrm{d}}$, he finds that where the radius of the Sun's eccentric $R=60$, the eccentricity $e=2 ; 29,30 \approx 2 ; 30$ so that $e / R=1 / 24$, the maximum equation $c_{\mathrm{m}}=2 ; 23^{\circ}$, and the direction of the apogee $\lambda_{A}=65 ; 30^{\circ}$. He concludes that the eccentricity has not changed and the apogee is tropically fixed. Taking twice the modern eccentricity, in -145 , the time of Hipparchus, $e=2 ; 6,22, c_{m}=2 ; 1^{\circ}$, and $\lambda_{\mathrm{A}}=66 ; 16^{\circ}$; in 140 , the time of Ptolemy, $e=2 ; 5,37, c_{\mathrm{m}}=2 ; 0^{\circ}$, and $\lambda_{\mathrm{A}}=71 ; 6^{\circ}$. Hence, $e$ is in error by $+0 ; 24$ and $c_{\mathrm{m}}$ by $+0 ; 23^{\circ}$ and have barely changed, but $\lambda_{A}$ is in error by $-0 ; 46^{\circ}$ in -145 and $-5 ; 36^{\circ}$ in 140 , and its longitude has increased $+4 ; 50^{\circ}$ in 285 years, of which about $4^{\circ}$ is the precession of the equinoxes and $0 ; 50^{\circ}$ the proper or sidereal motion of the apsidal line.

7) As a result of the error in the mean longitude of the Sun, Ptolemy's measurements of longitudes of fundamental stars have a systematic error of just over $-1^{\circ}$. He therefore finds a difference in longitude of stars in the 265 years since Hipparchus of $2 ; 40^{\circ}$ when it should be just over $3 ; 40^{\circ}$, and corresponding differences are found from other early observations. These confirm Hipparchus's 
low estimate of the motion of the fixed stars, or precession of the equinoxes, of $1^{\circ}$ per century or $36^{\prime \prime}$ per year, less by about $-14^{\prime \prime}$ than the correct $50^{\prime \prime}$ per year or $1^{\circ}$ in 72 years. The error in the tropical longitude of stars accumulates at the rate of $-0 ; 23,20^{\circ}$ per century.

So much for the errors and their consequences in Ptolemy's astronomy. The more interesting story begins several hundred years later when Arabic astronomers derived parameters from their own observations of the Sun and stars, and used Ptolemy's observations for finding motions over the intervening period. Without exception, compared to Ptolemy's parameters, it was found that: the obliquity of the ecliptic is smaller, the tropical year shorter, the eccentricity of the Sun smaller, the solar apogee advanced in longitude, and the motion of the fixed stars faster. What is to be done? One solution, for example by al-Battāni, was to accept the new parameters as correct and Ptolemy's, by implication, as erroneous.' And it was concluded, for example in De anno solis attributed to Thăbit ibn Qurra, that Hipparchus's observations of equinoxes and longitudes of stars were preferable to Ptolemy's for finding the length of the sidereal and tropical year and the motion of the fixed stars, which accounts for their difference. But another, more complex solution was to assume that the parameters had changed over the intervening centuries and develop models and parameters for these long-period variations. Among those that came to be known in Europe are a model for a nonuniform motion of the "eighth sphere," of the fixed stars, in De motu octavae sphaerae attributed (incorrectly) to Thābit, included in the Toledan Tables, a model for a variation of the solar eccentricity by az-Zarqãl, not included in the Toledan Tables, and a very well-known nonuniform motion of the eight sphere in the Alfonsine Tables, for which there are tables but no model. The apogees of the Sun and planets were taken to be sidereally fixed, and thus to follow the motion of the eight sphere, and the apogee of the Sun was sometimes given its own proper sidereal motion. Implicit in models for the motion of the eight sphere is a variation of the obliquity of the ecliptic, although this was, it appears, not tabulated as a variable parameter, nor was an implied variation in the length of the tropical or sidereal year tabulated. The last thing these theories can be called is consistent. In the Theoricae novae planetarum, Peurbach described his understanding of the model in De motu octavae sphaerae and explained what may be his own model for the Alfonsine motion. Regiomontanus considered both theories to be false (mendacem), which was his opinion of the Alfonsine Tables in general.

All of these attempts to include long-period variation of parameters were superseded by Copernicus, who developed more or less consistent models of some complexity, based upon motions of the Earth rather than the sphere of the fixed stars and the Sun, for nonuniform variations of the obliquity of the ecliptic, rate of the "precession of the equinoxes" (Copernicus's own term), length of the tropical year, solar eccentricity, and sidereal and tropical motion of the solar apogee. Copernicus's models were described and the parameters derived, with some wishful thinking, in De revolutionibus (1543), and all the long-period motions were included in Erasmus Reinhold's Prutenic Tables (1551), which became the basis for the computation of ephemerides in the later sixteenth and early seventeenth centuries. And Copernicus's 
models were carried over into geocentric theory, as by Giovanni Magini, by transferring the various motions of the Earth to the sphere of the fixed stars and the Sun. Hence, the complex legacy of the errors in Ptolemy's solar observations was fundamental to the astronomy in this period in both theory and tables. But already questions were being raised about the reliability of the observations. Copernicus told Rheticus of his fear that very many of the observations of the ancients were not genuine but were accommodated to their theory, as Rheticus reports in his Ephemerides novae (1550), although these doubts may have come after Copernicus erected much of his astronomy upon these very observations. Girolamo Cardano, in De restitutione temporum et motuum coelestium (1543), attempted, after a fashion, to find the cause of error and correct some of Ptolemy's observations and parameters, although he was more critical of Thäbit's motion of the eighth sphere and the Alfonsine Tables. A more expert examination did not come until the ancient observations and parameters were considered by Tycho, who intended more than he accomplished, Tycho's former assistant Christian Longomontanus, who set out the most radical criticism and correction, and Kepler, who had his own reasons for carrying out such an investigation. In this paper, we shall consider all three. ${ }^{2}$

\section{Tycho Brahe}

It is commonly said that Tycho did away with all the long-period yariation of parameters that had so concerned Copernicus and established new and improved parameters for the obliquity, solar theory, and precession on the basis of his own observations, more accurate than any that came before. There is some truth in this, as he did all of these things, but in the Progymnasmata he explains several times that the parameters established here are only for his own time and he intends to investigate their variation over a long period in a complete restoration of astronomy, which was never written. In fact, Tycho always believed with Copernicus that the obliquity of the ecliptic and the solar eccentricity had decreased and the apsidal line advanced from antiquity to his own time, meaning that he took the observations and theory of Hipparchus and Ptolemy seriously, although he never worked out a hypothesis, model, of his own for long-period variation. Initially, he accepted Copernicus's hypothesis for the Sun, but because Copernicus's eccentricity was smaller than he found, he concluded that it must be erroneous. In a letter of 4 November $1580(7.59-60)$ he tells Thadaeus Hagecius of a restoration of the motion of the Sun, which he investigated in preceding years, so careful that it agrees with daily observations, as (Paul) Wittich often tested with me, from which the computation of Alfonso and Copernicus deviates sometimes by half a degree, sometimes by a little more. For the motion of the center of the eccentric of the Sun in its small circle is far different than our predecessors found, or even Copernicus himself established, so that the eccentricity of the Sun is now 2;5 parts (where the radius of the eccentric is 60), 0;13 greater than the opinion of Copernicus, but the apogee of the Sun is near Cancer $5^{\circ}$, far before (west of) the hypotheses of Copernicus. ${ }^{3}$ For otherwise the solar appearances do not agree, as I have demonstrated from many observations and will soon, God willing, communicate to the learned. Tycho thus 
accepts Copernicus's hypothesis with variable eccentricity and apsidal line, but is attempting to correct the parameters, and the same is true of the variable precession. For I have also discovered, he reports, that the motion of the eighth sphere (of the fixed stars) is now so much faster than Copernicus established that the equinox has precessed about one-quarter degree faster (in the period since Copernicus), which, by observation of Spica made in the same way as Copernicus, I have observed and demonstrated many times.

In the Progymnasmata, Tycho establishes a solar theory from his own observations in the years 1584-1588, which he considers more accurate than any earlier observations because he corrects for solar parallax, which he believes reaches $3^{\prime}$ in the horizon, the standard value since Ptolemy, and refraction, reaching $34^{\prime}$ in the horizon. In 1584 he found his definitive value of the obliquity, $23 ; 31,30^{\circ}$, which he continued to check in the following years. For his derivation of the solar eccentricity and direction of the apogee (2.19-23), he uses the two equinoxes and Taurus $15^{\circ}$ or Leo $15^{\circ}$, following the method described by Regiomontanus in the Epitome of the Almagest 3.14. Copernicus had done something like this in De revolutionibus 3.16 using Scorpio $15^{\circ}$, which, Tycho points out, led to errors due to neglect of refraction at a low altitude although he believes that Copernicus did correct for parallax. From two derivations for 1588 , he finds that where $R=100,000, e=3584$, or where $R=60, e \approx 2 ; 9, c_{\mathrm{m}} \approx 2 ; 3,15^{\circ}$, and $\lambda_{\mathrm{A}}=$ Cancer $5 ; 30^{\circ}$, which he says are confirmed by yet other derivations. But he does not believe the parameters are permanent, indeed, with Copernicus, he had reason to believe that the solar eccentricity decreased and the longitude of the apogee increased since antiquity, as he explains (2.28). Hipparchus and Ptolemy found by observation at their times $\lambda_{\mathrm{A}}=$ Gemini $5 ; 30^{\circ}$ and $e=415$ where $R=10,000$, so $c_{\mathrm{m}}=2 ; 23^{\circ}$, and since Ptolemy found these again in the same way as Hipparchus, before him by an interval of 260 years, he believed the apogee entirely immovable and the eccentricity to remain for ever the same. It may, however, be suspected that some error is concealed in the observations of both or at least one of them, which could easily happen in so sensitive an undertaking, especially because they began their demonstration in this investigation through equinoxes combined with transits of the solstice, which are observed with great difficulty. And it is likely that Ptolemy, because he did not find so great a difference, did not wish to disagree with the records of Hipparchus, but instead assigned to his own age the same eccentricity of the Sun and the same apogee, affirming too confidently for this reason that both are immovable. He goes on to review briefiy, following the Epitome of the Almagest and De revolutionibus, the solar theories of al-Battānī and az-Zarqāl, and then carries out a detailed analysis of the errors in Copernicus's solar theory because Copernicus found a smaller eccentricity and a more advanced apsidal line for 1515 than he found for 1588 , contradicting in a mere 73 years the record of nearly 1450 years since Ptolemy. Thus, Tycho still believes that a notable variation of the eccentricity and advance of the apsidal line have occurred, that the theory of Hipparchus and Ptolemy, although open to question, must still be taken seriously, but that Copernicus's own hypothesis and parameters are incorrect.

And there is more, for Tycho also believes, with Copernicus, that the length of the tropical year has varied from antiquity to his own time, as evidence for which 
he presents the following comparisons in days and hours to which we have added sexagesimal fractions of days (2.33):

\section{From Hipparchus to Ptolemy}

From Ptolemy to al-Battãni

From al-Battānī to our observations

From Ptolemy to our observations

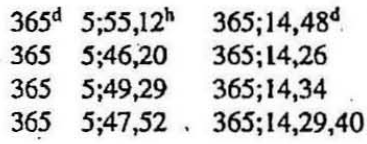

That the year is nonuniform and has become shorter since antiquity is apparent, although it is also apparent that the values cited here are not consistent and something is wrong, as Tycho recognizes. What could cause such a variation? Tycho explains that the inequality of the tropical year is the result of the variation of the apogee and eccentricity of the Sun producing a motion of the ecliptic, on account of which the equinoctial points recede along the equator with respect to the fixed stars. Thus, the inequality of the year is the result of inequalities in the motion of the Sun affecting the location of the equinoxes, the precession of the equinoxes is a part of solar theory, and there is no motion of the sphere of the fixed stars, which he considers at rest except for the diurnal rotation of the heavens. This is a difficult subject, the interpretation and cause of precession, the theory of which Tycho never fully worked out although he later suggested something like his model for the regression of the nodes in the lunar latitude theory, and we shall return to it below.

Also with Copernicus, Tycho believes the sidereal year invariable, and this is of some interest as it is in finding the length of the sidereal year that he makes the most direct use of Ptolemy's observations and theory (2.33-37). That earlier values differ, he says, is because of errors in observation, failure to take account of solar parallax and refraction, insufficiently accurate locations of fixed stars, or from all of these causes coming together, as could easily happen in so sensitive an investigation. Of earlier values, he cites, from the Latin version of al-Battāni, "the most ancient Egyptians and Babylonians," $365 \frac{1}{4}+\frac{1}{131}^{d}=365 ; 15,27,30^{d}=365^{d} 6 ; 11^{\text {h }}$; Thäbit ibn Qurra, $365 ; 15,23^{d}=365^{d} 6 ; 9,12^{\mathrm{h}}$; and Copernicus, $365 ; 15,24,10^{\mathrm{d}}=$ $365^{\mathrm{d}} 6 ; 9,40^{\mathrm{h}}$. Then, in order that we may find the length of the sidereal year more accurately, we have carefully compared Ptolemy's observations of the Sun and fixed stars with our own, for I am convinced that his observations are more accurate and secure than those of Hipparchus: (Delambre calls this a "choix singulier.") What Tycho does is use Ptolemy's solar theory and tropical longitude of fixed stars as correct for Ptolemy's time, and his own solar theory and longitude of fixed stars as correct for his own time, to find the sidereal longitude of the Sun at each time. He also assumes that Ptolemy's rate of precession, $36^{\prime \prime}$ per year, is correct for Ptolemy's time and his own rate, $51^{\prime \prime}$ per year, not yet set out, is correct for his own time. And like Copernicus, he takes the longitude of the first star of Aries in Ptolemy's catalogue, $\gamma$ Arietis, as the measure of precession.

Thus, at Ptolemy's autumnal equinox (11) of 25 September 132 at $2^{\text {h }}$ after noon in Alexandria, the true longitude of the Sun $\lambda_{s}=180^{\circ}$ and the mean longitude $\bar{\lambda}_{s}=180^{\circ}+2 ; 10^{\circ}=182 ; 10^{\circ}$. Taking Ptolemy's longitude of Regulus on 23 February 139 of $122 ; 30^{\circ}$ and the interval to $\gamma$ Arietis of $-115 ; 50^{\circ}$, the longitude 
of $\gamma$ Arietis is $6 ; 40^{\circ}$, as in Ptolemy's star catalogue. Since for 6 years and 7 months (corr. 5 months) earlier $\Delta \pi=-4^{\prime}, \pi=6 ; 36^{\circ}$ and the mean sidereal longitude of the Sun $\bar{\lambda}_{3}^{*}=182 ; 10^{\circ}-6 ; 36^{\circ}=175 ; 34^{\circ}$. At Tycho's autumnal equinox of 12 September 1588 at $15 ; 15^{\mathrm{h}}$ after noon ( 13 Sep $3 ; 15 \mathrm{AM}$ ) at Uraniborg, $\lambda_{s}=180^{\circ}$ and $\bar{\lambda}_{s}=180^{\circ}+2 ; 2 \frac{1}{2}^{\circ}=182 ; 2,30^{\circ}$. From our observations, he says, at this time the precession of the equinoxes $\pi=28 ; 5 \frac{1}{2}^{\circ}$ - as we shall show in the following chapter from accurate observations made earlier-so the mean sidereal longitude of the Sun $\bar{\lambda}_{s}^{*}=182 ; 2,30^{\circ}-28 ; 5,30^{\circ}=153 ; 57^{\circ} .4$ The difference in sidereal longitude $\Delta \bar{\lambda}_{\mathrm{s}}^{*}=153 ; 57^{\circ}-175 ; 34^{\circ}=-21 ; 37^{\circ}=+338 ; 23^{\circ}$. Next, in his list of longitudes and latitudes of places $(5.309-10)$, the difference in longitude of Alexandria and Uraniborg is $60 ; 30^{\circ}-36 ; 45^{\circ}=23 ; 45^{\circ}=1 ; 35^{\mathrm{h}}$ (corr. $\left.29 ; 55^{\circ}-12 ; 42^{\circ}=17 ; 13^{\circ}=1 ; 9^{\mathrm{h}}\right)$. Hence, at the meridian of Uraniborg, the time of Ptolemy's equinox is $2^{\mathrm{h}}-1 ; 35^{\mathrm{h}}=0 ; 25^{\mathrm{h}}$ after noon. Now, between the two autumnal equinoxes, including complete revolutions and years, the difference of mean sidereal longitude $\Delta \bar{\lambda}_{s}^{*}=1455^{\mathrm{r}}+338 ; 23^{\circ}$ and the difference of time in Julian years $\Delta t=1455^{\mathrm{jy}}+355^{\mathrm{d}} 14 ; 50^{\mathrm{h}}$. Thus, the mean sidereal motion of the Sun $\vec{\nu}_{s}^{*}$ and the length of the sidereal year sy are:

$$
\begin{aligned}
& \bar{v}_{s}^{*}=\frac{524138 ; 23^{\circ}}{531791 ; 37,5^{d}}=0 ; 59,8,11,27,14,26,54^{\circ / d}, \\
& s y=360^{\circ} / \bar{\nu}_{s}^{*}=365^{d} 6 ; 9,26,43 \frac{1}{2}^{h} .
\end{aligned}
$$

The correct length of the sidereal year is $365^{d} 6 ; 9,10^{\text {h }}$, about $17^{\prime \prime}$ less, which accumulates to $1^{\text {h }}$ in 212 years and nearly $7^{\text {h }}$ in the 1456 years since Ptolemy's equinox. The principal cause of the difference is an error of about $-30^{\mathrm{h}}$ in $\Delta t$, from Ptolemy's equinox, which is $33^{\text {h }}$ late, compensated slightly by Tycho's, about $3^{\text {h }}$ late.

Tycho does better with the tropical year, for which his goal is more modest but the required work greater (2.37-45). He explains that he does not here attempt a complete restitution of the solar motion for all ages, which he decided to reserve for his complete work of restored astronomy, but only as suffices for the nearest periods, within 300 or 400 years, for in that time an inequality in the tropical year that disturbs what we propose to do cannot occur. Therefore, instead of using the sidereal year and separating out the precession of the equinoxes, which would here be very lengthy (because over long periods the precession is variable), we shall instead be satisfied with the equinoctial or tropical year confirmed for this very period. We shall investigate this from observations of meridian altitudes of the Sun a hundred years ago in Nuremberg by the learned Bernhard Walther, of lasting memory and especially worthy of praise, the distinguished student of Regiomontanus. What he then does is derive the parameters of solar theory for the year 1488 using Walther's observations of chords of meridian zenith distances of the Sun to locate the Sun at the equinoxes and at Taurus $15^{\circ}$ and Leo $15^{\circ}$, and from two derivations settles on $e=0.035481, c_{\mathrm{m}}=2 ; 2^{\circ}$, and $\lambda_{\mathrm{A}}=$ Cancer $4 ; 15^{\circ}$. Note that $e$ and $c_{\mathrm{m}}$ are slightly smaller than Tycho's for 1588 , and he also finds an obliquity of $23 ; 31^{\circ}$, slightly 
less than his own $23 ; 31,30^{\circ}$. He takes these differences seriously and remarks that it seems consistent that from that time the obliquity of the ecliptic has increased slightly, because meanwhile the eccentricity of the Sun has also increased somewhat, and not (as the Copernican reasoning erroneously maintains) decreased. Then, from the difference in time between the equinoxes, both vernal and autumnal, of 1488 and 1588 - with small errors in the differences in longitude of Nuremberg and Uraniborg and in the mean longitudes of the Sun-he derives for the length of the tropical year $365^{\mathrm{d}} 5 ; 48,45^{\mathrm{h}}$ exactly, an excellent value. The mean daily motion is computed to no less than seven places, of which the first four are $0 ; 59,8,19,49^{\circ / d}$. The epoch for noon of $1 \operatorname{Tan} 1588$ is $290 ; 4,50^{\circ}$.

Since Tycho considers the tropical year variable over longer periods, the mean motion is intended for a limited time, and he tabulates epochs only for the period $1400-1800$, that is, $1600 \pm 200$ years. The rate of precession is later found (2.253) from the difference between the sidereal and tropical year, $365^{\mathrm{d}} 6 ; 9,27^{\mathrm{h}}-365^{\mathrm{d}} 5 ; 48$, $45^{\mathrm{h}}=0 ; 20,42^{\mathrm{h}}$. Since the Sun moves about $0 ; 2,28^{\circ / \mathrm{h}}$, the precession $\pi=$ $0 ; 2,28^{\circ / \mathrm{h}} \cdot 0 ; 20,42^{\mathrm{h}} \approx 51^{\prime \prime}$ per year, $1^{\circ}$ in 70 years and 7 months, which will be confirmed for longer periods from observations of fixed stars. It was found that in $1488 \lambda_{\mathrm{A}}=94 ; 15^{\circ}$ and in $1588 \lambda_{\mathrm{A}}=95 ; 30^{\circ}$, a change of $1 ; 15^{\circ}$ in 100 years, from which the motion of the apogee is $45^{\prime \prime}$ per year. Since the precession is $51^{\prime \prime}$ per year, the sidereal motion of the solar apogee is $-6^{\prime \prime}$ per year, that is, retrograde, which Tycho does not mention. But since it may not be uniform over longer periods, perhaps at some other time it is direct. This then is the solar theory Tycho established for his own time and two centuries before and after. Although doubts have been raised about Ptolemy's solar observations and theory and observations of fixed stars, they have not been rejected, but in fact accepted for the determination of the sidereal year.

Tycho has more doubts about the observations of fixed stars used to confirm the rate of precession. He has no confidence in any earlier determination of precession: Ptolemy's $1^{\circ}$ in 100 years is too slow, al-Battānī's $1^{\circ}$ in 66 years is too fast, and Copernicus's variable precession is defective, as we shall see below. Nor does he consider earlier coordinates of stars reliable, although he does use some to confirm his own rate of precession. And he believes that Ptolemy's catalogue of stars is that of Hipparchus corrected for precession (2.151). "After these (Timocharis and Hipparchus), Claudius Ptolemy also, about the year 140 after the birth of Christ, and at Alexandria in Egypt, attempted to observe and commit to writing some amount in the advancement of these (stars, nonnulla in harum progressione), yet concerning the placement of them with respect to each other in longitude and latitude completely preserving the Hipparchan table." And the same is true of the catalogues of Battānī, Alfonso, and Copernicus, so in this sense, there has been only one star catalogue, that of Hipparchus, successively adjusted for precession.

We have seen that Tycho accepts long-period variation of parameters of solar theory, the eccentricity, direction of the apogee, length of the tropical year, and also, as we shall see, the obliquity of the ecliptic and the precession of the equinoxes, to which the variation in the length of the tropical year is related. Several times he states that the parameters derived here are only for the closest periods, and he 
also says that their definitive examination for all ages is deferred to his complete restoration of astronomy, which he never wrote. Although he admits the possibility of smaller errors, nowhere does he say that Hipparchus and Ptolemy were absolutely wrong about the eccentricity of the Sun, the direction of the apsidal line, the length of the tropical year, and the obliquity of the ecliptic, which thus have changed notably since antiquity. But the most important problem is the precession of the equinoxes or, as Tycho prefers, the (apparent) motion of the fixed stars: is it uniform or nonuniform over long periods and what is its cause? We begin with Tycho's treatment in the Progymnasmata, which comes after the establishment of locations of fundamental stars for the star catalogue and the explanation of how locations of other stars are found. The section is called "On the proper motion of the fixed stars corresponding to this age" (2.253-57). He begins with the derivation of the rate of precession from the difference of the sidereal and tropical years we have just shown. The length of the sidereal year is $365^{d} 6 ; 9,26,43^{\text {h }}$, the length of the tropical year "in this age" is $365^{\mathrm{d}} 5 ; 48,45^{\mathrm{h}}$, less than the sidereal year by about $0 ; 20,42^{\mathrm{h}}$. In so much time the Sun, after traversing an entire circle, again overtakes a fixed star which has advanced slightly, meanwhile passing over exactly $51^{\prime \prime}$ in its motion, and therefore such a small amount is the annual advancement of the fixed stars "in our age."

He then sets out confirmations of this rate using pairs of locations of Spica and Regulus from observations of his own, Copernicus, Battāni, Ptolemy, Hipparchus, and Timocharis. We summarize these in the following table giving the observers, star, earlier and later longitudes $\lambda_{1}$ and $\lambda_{2}$, difference in longitude $\Delta \lambda=\lambda_{2}-$ $\lambda_{1}$, difference in time $\Delta t$ in years, and the annual rate of precession $\pi=\Delta \lambda / \Delta t$ computed by Tycho.

\begin{tabular}{|c|c|c|c|c|c|c|}
\hline Observers & Star & $\lambda_{1}$ & $\lambda_{2}$ & $\Delta \lambda$ & $\Delta t$ & $\pi$ \\
\hline Cop.-Tycho & Spica & $197 ; 3,30^{\circ}$ & $198 ; 3^{\circ}$ & $0 ; 59,30^{\circ}$ & $70^{y}$ & $0 ; 0,51^{\circ / 4}$ \\
\hline Hip.-Tycho & Regulus & $119 ; 50$ & $144 ; 5$ & $24 ; 15$ & 1713 & $0 ; 0,50,59,47$ \\
\hline Hip.-Bat. & Regulus & $119 ; 50$ & $134 ; 5$ & $14 ; 15$ & 1006 & $0 ; 0,51$ \\
\hline Bat.-Tycho & Regulus & $134 ; 5$ & $144 ; 5$ & $10 ; 0$ & 705 & $0 ; 0,51,4$ \\
\hline Tim.-Tycho & Spica & $172 ; 20$ & $198 ; 3$ & $25 ; 43$ & 1879 & $0 ; 0,49,15$ \\
\hline Ptol.-Tycho & Spica & $176 ; 40$ & $198 ; 3$ & $22 ; 23$ & 1446 & $0 ; 0,53,15$ \\
\hline
\end{tabular}

The results are not quite straightforward and most of the values of $\pi$ have small errors of little consequence. ${ }^{5}$ To explain the discrepancies of about $\pm 2^{\prime \prime}$ in the comparisons with Timocharis and Ptolemy, he notes that the comparison with Hipparchus in between them is correct, which is confirmed by al-Battānī, that the mean of their values is about $51^{\prime \prime}$, and that their observations are not sufficiently accurate for this purpose. For this reason, it is useless to give direct comparisons between Timocharis, Hipparchus, and Ptolemy, which would be close to Ptolemy's $36^{\prime \prime}$ per year. Hence, it appears that $51^{\prime \prime}$ per year is confirmed for nearly 1900 years. But Tycho is more cautious, for he writes that assuming that the annual motion of the fixed stars is exactly $51^{\prime \prime}$, in no way shall we depart from the required goal in 
any experiences that can occur in the nearest three or four centuries (as concerning more I shall not speak). Like the epochs of the Sun's mean motion, the epochs of the motion of the fixed stars are tabulated only for 1400-1800, as they are in the Restoration of the Fixed Stars with the catalogue of 1,000 stars completed in 1598 $(3.343,374)$. He goes on to say, and this seems to be his main point, that Copernicus's theory of the inequality of the precession of the equinoxes, to reconcile and preserve all the discoveries of his predecessors, is in no way correct, as in the motion of the seventy years from his first observation of Spica, which is much faster than he believed it would be, not one degree in about one hundred years but in seventy, and in the length of the tropical year, which is not as long as he believed, for according to Copernicus the two are connected such that the motion of the fixed stars is slowest when the year is longest. But the accurate observations of recent years refute this since they do not correspond in their periodic returns, meaning that the precession is not as slow or the tropical year as long as in Copernicus's theory. ${ }^{6} \mathrm{He}$ concludes (2.255-56):

It is not now our intention to set out the universal motion of the eighth sphere (as it is called) and also corresponding to all periods in the age of the world, so that the inequality discovered by first some and then other practitioners will, as far as possible, be justified, leaving aside the undertaking of such labor to a special restoring of astronomy. Nevertheless, convinced in this matter by good reasons, I do not hesitate to affirm that so immense an anomaly is hardly concealed in the motion of the fixed stars as is come upon from the observations of Timocharis and Ptolemy compared with Hipparchus and al-Battāni. For it is not likely that sometimes they pass over $1^{\circ}$ in 100 years, as Ptolemy reckoned, but sometimes in 66 years, as al-Battānī believed, but rather without doubt some error has escaped detection in the actual observations of the practitioners, which appears clearly enough from the fact that the longitudes of the very stars they report specifically to have observed are not distant from each other in heaven itself by the amount their record claims, so much so that a deviation from the arrangement of heaven is found of a third and even half a degree, which will be clear to anyone by comparing our intervals of longitude with their records regarding the same stars. We also see how little of more refined accuracy the moderns have shown in these matters, as is clear from the published observations of Regiomontanus and his student Bernhard Walther, and of Werner. Nevertheless, I shall not suppose that the observations of the ancients of the fixed stars were so erroneous that it cannot be gathered from them that some kind of inequality of motion is concealed in them, although I believe this takes place from some external cause and indirectly, and with good reason is not to be attributed to the stars themselves. Still, it is not yet suitable to make known a final judgment on this matter, considering more deliberately to reserve it to the comprehensive study of astronomy to be published in several years. 
Although the comprehensive study of astronomy was never written, Tycho does say more on the question in his correspondence with Joseph Scaliger. The correspondence, of considerable interest on both sides, has been treated in detail by Anthony Grafton (1993) concerning Tycho's correction, or attempted correction, of Scaliger's notions about the sidereal year and precession, and our own examination of this curious subject owes much to Grafton's. Tycho knew Scaliger's work well. In 1584 he asked his friend Heinrich Brucaeus, Professor of Medicine at Rostock, for a copy of the recently published De emendatione temporum, the first of Scaliger's two great works on chronology, which Brucaeus promptly sent. In 1595, through his former assistant Johann Isaac Pontanus, then in Amsterdam, he sent Scaliger in Leiden several printed quaternions of the solar theory in the Progymnasmata so that he could compare his equinoxes with ancient equinoxes to find a more correct measure of the relation of the tropical and Julian year. He hoped that in this way the length of the tropical year, which he had established for the recent period from Walther's observations, could be found more accurately by extending the interval back to antiquity and in so doing refute Copernicus's theory of the variation of the tropical year and precession, which he says is not as great or as important as astronomers suspect (7.373-74). He seemed to think that Scaliger had original reports of ancient observations of equinoxes, by Hipparchus in particular, other than the citations in the Almagest, which of course he did not. In a letter of $14 \mathrm{March}$ 1598 written from Wandesburg (8.31-33), he asks Scaliger to send him all Hipparchus's observations he has of vernal and autumnal equinoxes, perhaps from the Commentary on Aratus which contains no such equinoxes, set out in a table so that he could compare them with his equinoxes; if he has other very old observations of equinoxes, he would wish them, and also the most ancient epoch of the Jews, when it is believed the equinox took place on 21 April at 6 hours after noon. This would have been about $3800 \mathrm{BC}$, close to the date of Creation. Scaliger included Tycho's equinoxes in the second edition of De emendatione temporum (1598), and concluded from a comparison of Hipparchus's and Tycho's equinoxes that the Alfonsine tropical year of $365^{\mathrm{d}} 5 ; 49,16^{\mathrm{h}}$ is correct and preferable to the year of "Gelalaeus."7

Now on 9 July 1598 Scaliger sent Tycho the second edition of De emendatione temporum with a letter setting out his ideas about the tropical and sidereal years and the precession (8.83-87). He believes that the sidereal year is not longer than, but equal to, the Julian year, because the same star always rises in the evening and sets in the morning on the same Julian date, which in truth the judgment of the Egyptians that decrees that Sirius always rises on the same Julian date proved to us, the evidence for which is that what we call the Julian year the Egyptians called "Canicular" because for more than 1500 years Sirius (Canicula) rose on the same date of the Julian year. This observation, as I hope, he tells Tycho, will not be unwelcome to you. He did not reach this conclusion from a record of Egyptian observations of the rising of Sirius, which does not exist, but, it appears, by interpreting the Sothic Cycle, 1461 Egyptian years $=1460$ Julian years, in which 1 Thoth in the Egyptian calendar returns to the same date in the Julian calendar, plus an additional 44 Julian years for the effect of the precession of the equinoxes, advancing the equinox by 11 
days in 1460 Julian years, as a period of more than 1500 Julian years in which Sirius rose on the same date. ${ }^{8}$ Further, he continues, there is no trepidation nor motion of the eighth sphere, of the fixed stars, from west to east because it is the equinoctial points in the ecliptic that move from east to west, for the equinoctial circles (of the equator) are described as a consequence of them. These points are surely movable, and therefore the circles described as a consequence of their motion are movable and consequently the pole of the equator is movable. And thus in the time of Hipparchus, the pole of the equator was distant from the tail of Cynosura (Polaris) by $12 ; 24^{\circ}$; now it is distant by less than $3^{\circ}$.

Scaliger's theory is this: the pole of the world, meaning of the sphere of the fixed stars, passes through the Pole Star itself or is not far removed from it, and the pole of the world, the arctic and antarctic circles, and the fixed stars do not move at all-aside from the daily rotation-there is no motion of the eighth sphere. Instead, the pole of the equator is movable, and has never been the pole of the world although at some time it will be as it is approaching closer to the Pole Star. As a consequence of the motion of the pole of the equator, the equator moves along the ecliptic and the tropic circles also move parallel to the equator-these circles are not parallel to the arctic and antarctic circles - and it is this motion that produces the precession of the equinoxes and solstices. Just how Scaliger came up with this explanation of precession, which he regarded as eliminating the motion of the fixed stars, is not certain. He was no Copernican in the sense of holding the heliocentric theory and the motion of the Earth, but it may have been an attempt to adapt Copernicus's theory of precession, which is a motion of the equator along the ecliptic while the fixed stars and the ecliptic do not move, to an unmoving central Earth and unmoving sphere of the fixed stars, although without Copernicus's inequalities which Scaliger definitely rejects.

Tycho wrote a long, detailed, and patient answer from Wandesburg between 17 and 23 August $1598(8.100-09)$. He had his work cut out for him. He says he cannot support Scaliger in his proposal concerning the equator and its movable poles and that they differ from the poles of the world as his experience from instruments is otherwise (8.102-02).

For I have found from the change in latitude of fixed stars in accordance with the proportion of the change in the obliquity of the ecliptic from the times of Timocharis, Hipparchus, and Ptolemy up to the present (if only what they observed in the angle of the maximum obliquity and the rest are free of any error, concerning which, not without reasons I am in doubt) that it is the ecliptic that is unstable rather than the equator with its poles, the Sun not always describing the same ecliptic through a great interval of centuries, and at the same time successively anticipating the places at which it crosses the equator. Hence, it happens that the fixed stars appear to progress as much as the Sun returns earlier to these points. And since what fits the deficit of the tropical year from the Julian year is clearly not equal to that motion, it is not possible that the fixed stars rise or set with the Sun on the same days of the Julian year through intervals of several centuries, and likewise from other 
concurrent causes which will give rise to a discrepancy. And although it (the rising of stars) can somehow coincide (with the same days of the Julian year) for some few stars for a long interval of years, nevertheless not always or for all stars. Also, there is no difference at all between the pole of the equator and of the world, as you infer both in your book and here, for they are one and the same. And the last star in the tail of Ursa Minor, called Polaris because it is near the pole, is not the pole of the world or the closest to it unless you understand that to mean the pole of the equator, which, as I said, does not differ from the pole of the world. This star was distant from the pole of the equator by $12 \frac{2}{5}$ in the time of Hipparchus, but in this year according to our discoveries it has approached it within $2 ; 51 \frac{1}{2}^{\circ}$, as 25 years earlier we found it removed from the pole by precisely $3^{\circ}$ with a quadrant 14 cubits in radius in the garden near the estate of Councillor Heinzel in Augsburg. The approach to the pole of the equator or of the world takes place, not because this star is the pole or near (the pole) of any sphere, but through its change of longitude about the poles of the ecliptic, by which its declination increases, since it is now near the end of Gemini but at the time of Hipparchus was near the end of Taurus, in the intervening time having covered a little more than $24^{\circ}$ in longitude, but in latitude altered not more than the decrease of the obliquity of the ecliptic produces, through a third part of a degree (if it is even that much), for the (latitude) which the table of Ptolemy places at $66^{\circ}$ exactly is approximately confirmed. And if this star is referred to the equator in our own age, it will not fall in the equinoctial colure, as perhaps you believe, but will be removed from it by $5 \frac{3}{4}^{\circ}$ of the equator, as has itself been demonstrated by certain experience. But it can never be exactly united with the pole of the equator, for after about 500 years, when the beginning of Cancer reaches the solstitial colure, it will be distant from the pole toward the equator or ecliptic by $27 \frac{1}{2}^{\prime}$. For although the inclination of the ecliptic will perhaps then be increased a little (which, however, I scarcely think will come about), yet this will alter only the latitude of the star and not on account of that move it closer to the pole, as the stars definitely look to the fixed poles of the ecliptic while the Sun describes somewhat movable poles through the ages (i.e. a movable ecliptic with movable poles), in so far as the records of the ancients are worthy to be trusted.

Tycho goes on to explain that the heliacal rising of Sirius changed, according to his computation, by only one day in the Julian year for 1500 years before Ptolemy, which would have been difficult to detect, not because the sidereal year is equal to the Julian year, but by chance in that particular star because in the interval of so many centuries its declination changed by $2 \frac{2}{3}^{\circ}$ such that this alteration of declination corrects and nearly eliminates the change that could occur from the difference between the Julian and sidereal year. This explanation, which Tycho was surely the first to formulate, is correct. ${ }^{10}$ But our concern here is not so much Tycho's correction of Scaliger, as his own ideas concerning the precession, which he says is - a result, not of the motion of the fixed stars, but of the ecliptic. He enlarges on this 
in correcting Scaliger's dismissal of the sidereal year and its relation to precession (8.103-04).

The calculation of the sidereal year, introduced by the Babylonians and Egyptians and after that improved by Thābit, but restored in our age by Copernicus, is not so empty and useless as you think, if only it is determined exactly. We have corrected it still more accurately in our Progymnasmata astronomica in so far as Ptolemaic observations are compared with our own. But when through you I receive the Hipparchan observations in some quantity, I will examine this more precisely. For with you, I also consider it preferable to depend upon Hipparchus than Ptolemy. However, I believe no less than Copernicus that with respect to themselves the fixed stars remain forever unmoved. But I do not allow that progression, which they appear to make, through the precession and libration of the axis of the Earth, as he (Copernicus) preferred, since in truth nothing of the kind is suitable to the Earth. But if the reports of the ancients are worthy to be considered in every way certain, it will be very likely that the Sun itself describes one and another ecliptic in different ages. And however small the inequality concealed in it could be, in so far as it will be permitted to explain from past observations of the practitioners, we shall, God willing, save it through the universal hypothesis of the Sun. And . the calculation of the sidereal year will also be of use for this purpose, as also for finding the simple motion of the planets from a fixed and immovable point and establishing it more accurately than up to now.

The "Hipparchan observations" refer to the original reports or additional observations, especially of equinoxes, Tycho requested earlier-the next year Scaliger sent him a copy of the Commentary on Aratus, in which he would have seen that it contained nothing of the kind-and again he asks. for the most ancient equinox of the Jews. The meaning of the sentence about believing with Copernicus that the fixed stars are forever unmoved is, not that they do not move among themselves, which everyone believes, but that the fixed stars as a whole, the sphere of the fixed stars itself, is unmoved, as Copernicus alone believed and as Scaliger and Tycho now also believe, which is confirmed by the statement that the simple (sidereal) motion of the planets be found from a fixed, immovable point, as Copernicus also held. The only motion of the sphere of the fixed stars is the diurnal rotation about the pole of the equator, which Tycho considers the pole of the world and absolutely fixed. Instead, the precession is due, not to the motion of the stars, but to the motion of the Sun, describing different ecliptics in different ages, possibly with a small inequality. This agrees with his statement that the Sun does not always describe the same ecliptic through a great interval of centuries, and at the same time successively anticipates the places at which it crosses the equator, so that the fixed stars appear to progress as much as the Sun returns earlier to these points.

The discussion, the issue, between Tycho and Scaliger is this: Both believe with Copernicus that the fixed stars do not move at all, that there is no motion of the eighth sphere, although they also believe, differing from Copernicus, that the diurnal rotation is of the entire universe, including the sphere of the fixed stars, about 
an unmoving, central Earth. But again with Copernicus both believe there is a precession of the equinoxes with respect to the fixed stars which is not caused by any motion of the stars. Scaliger believes the precession is caused by a motion of the pole of the equator with respect to the pole of the world, of the sphere of the fixed stars, at or very near Polaris, shifting the equator and thus the intersections of the equator with the ecliptic, the equinoxes, with respect to the stars and the ecliptic, which is also fixed with respect to the stars. This appears to be an adaptation to a fixed, central Earth of Copernicus's theory, in which the equator moves with respect to the ecliptic and the fixed stars, although without the inequality in the motion of the equinoxes. Scaliger also believes that the sidereal year is equal to the Julian year, as shown by the constant Julian date of the rising of Sirius, and those who say it is longer are simply wrong. Tycho believes instead that the pole of the equator is the fixed pole of the world and that the precession is the result of the motion of the Sun, describing successively different ecliptics, that is, an ecliptic that moves, rotates, along the equator so that the Sun crosses the equator at successively different points, causing the equinoxes to precess with respect to the fixed stars and fixed equator. There is probably also some small inequality concealed in this motion of the equinoxes, which accounts for the variation of the length of the tropical year, but the sidereal year, the Sun's return with respect to the fixed stars, is constant, as the fixed stars do not move, and is longer than a Julian year. The nearly fixed Julian date of the rising of Sirius is fortuitous, because the star's change in declination nearly compensates the difference between the sidereal and Julian year, which is not true of most stars. Tycho believes that he has established the length of the constant sidereal year correctly for all times and the length of the variable tropical year for 100 years since Walther and probably for 200 years before and after his own time; more than that and a complete explanation of the precession is reserved for his universal hypothesis of the Sun.

Scaliger was not convinced by Tycho's arguments, indeed, he became more certain than ever that he, the philologist with a profound knowledge of antiquity, was correct, and Tycho, the astronomer, and all other astronomers, who know nothing of antiquity, were wrong. He was writing a Diatribe on the precession of the equinoxes (De aequinoctiorum anticipatione diatriba), completed in 1601 but probably never seen by Tycho, and only published posthumously in $1613 .{ }^{11}$ On (NS) 10 March 1600 , he wrote to Tycho in Wittenberg (8.261-64), referring to a letter he had received recently, and summarizing what he planned to write in his Diatribe. The word "diatribe" then meant a critical dissertation, not necessarily an invective, although that is hardly lacking in Scaliger's Diatribe or his letter to Tycho (8.262-63).

For I intend to send you my diatribe on the precession of the equinoxes and refutation of the motion of the eighth sphere, in which we have both diligently assembled innumerable testimonies of the ancients and shall demonstrate by five clear testimonies of the most ancient authors that the star called Polaris has remained for 1966 years in the place where it is today. Further, we shall adduce so many incongruities and absurdities which follow from the 
hypothesis of the motion of the eighth sphere that there will be no one except the ignorant or envious who will dare speak to the contrary. I add also, because it has thus far been entirely unknown, that the precession of the equinoxes had been accepted from Thales and Anaximander up to the time of Hipparchus, and that Hipparchus was the first of all to reject it, having introduced the eastward motion of the eighth sphere, so that against the evidence of sight, he recorded the last star in the tail of Cynosura, or Polaris as it is commonly called, to be the most southern of all seven stars in that constellation, which nevertheless was before him, and is today, and will always be the most northern of all. See how the authority of such a man has misled posterity! For from him up to the present day, you believe such things, and for no reason

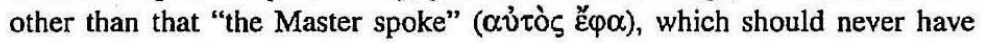
a place in mathematics. For to no sort of men has more harm been done by ignorance of antiquity than to the race of astrologers. Nothing occurs to me to be more surprising than that not one astrologer has had even a clue of the error of that hypothesis and how many and great are the absurdities necessarily born of it, if you except only Copernicus, who also recognized the precession of the equinoxes and the obliquity of the equinoctial circle (the equator), but through ignorance of antiquity took refuge in absurd hypotheses. In fact, the regular and uniform decrease of the maximum declination of the Sun necessarily follows from the precession of the equinoxes alone, which we have demonstrated completely, for otherwise it is not possible except by false hypotheses. Therefore it follows that the pole of the world differs from the pole of the equator, and that the meridian lines move and do not always remain in the same place, which we shall demonstrate perfectly from ancient authors.

Scaliger's history of precession may seem bizarre, but far more preposterous things have been written in our own time; indeed, precession always seems to inspire both learned and ignorant nonsense. The period of 1966 years during which the Pole Star has been in the same place is since Eudoxus as cited by Hipparchus, critically in fact, although Scaliger considers Eudoxus, with the likes of Thales and Anaximander, preferable to Hipparchus, the originator of the false understanding of precession as a motion of the fixed stars. This curious history, and there is far more of it in the Diatribe, has been treated at length by Grafton. It is clear that Tycho's attempt at correction had no effect, for Scaliger has changed his mind on nothing, and is certain that the testimony of some ancients correctly understood is of greater value to understanding precession than a sound knowledge of astronomy. Yet it can be said in Scaliger's defense that in the basic principle of moving the equator with respect to a fixed ecliptic and unmoving sphere of the fixed stars, in which he follows Copernicus, he is doing the right thing. Tycho answered in a letter written from Prague on (NS) 23 July 1600 (8.328-29), in which it appears that the great astronomer is not doing the right thing; the essential part is this:

I eagerly await your thoughts, which you promised, about saving the equinoxes and the motion of the eighth sphere in another way. I readily grant you that 
the Pole Star, just as all the other stars of the eighth sphere (as it is called), remains in the same place in heaven, if only you acknowledge in this star, as in the others, changes in declination and right ascension, as well as in longitude and even some change in latitude. I also agree with you that this will take place, not by the advance of the eighth sphere, but by the precession of the equinoxes, as the great Copernicus likewise seems to have apprehended. But the critical point in this matter turns upon how this precession is to be understood and accomplished. That it takes place, as Copernicus theorized, through a motion of the axis of the Earth, reciprocated and librated and not entirely coincident with the annual revolution, is in error; rather, the assumption is utterly absurd and does not satisfy the appearances in this age, much less in all other ages. I am convinced that the Sun itself causes this variation as it describes one and another ecliptic in different ages, and moreover draws the intersections of the ecliptic with the equator backwards, and in fact not at all uniformly, as I intend to show more fully, God willing, in its proper place. For I have discovered that the lowest Moon also varies its orbit in single months in a way not much different such that, not only does its maximum latitude vary up to a third part of a degree (in fact just as much as the difference thus far discovered in the obliquity of the ecliptic), but I also learned that the nodes and intersections with the ecliptic, although they move westward with a uniform motion, yet this takes place reciprocally and by a nonuniform quantity and a fairly notable difference which can reach $1 \frac{3}{4}^{\circ}$, as will be explained more completely, God willing, in publishing before long the restoration of the lunar motion in our Progymnasmata. If by chance there has become known to you a way different from ours by which these things can be explained properly, and it can be ascertained from ancient records and certain observations, I wish you to impart it to me. For the present, the matter is as I say, that I cannot comprehend what you have made known both in your letter and elsewhere: that the pole of the world is undoubtedly different from the pole of the equator and that meridian lines move. For it appears not quite suitable, unless perhaps I do not yet understand your meaning, which is rather obscure, so that concerning this matter I wish to be more fully instructed by you.

Tycho's answer is a lesson in gentle irony to a vain man who has nothing but abuse for those who do not submit to his teachings and acknowledge his genius. Since Scaliger's diatribe on precession has been considered by Grafton, we shall go on to our principal subject, Tycho's own explanation of precession in this letter, which appears to be the most complete statement of what he had in mind. The essential clue is the comparison to the model for lunar latitude, in which the inclination of the lunar orbit to the ecliptic is variable and the regression of the nodes along the ecliptic nonuniform. This model is to be transferred to the precession of the equinoxes, which, as we shall see, leads to problems.

Scaliger's and Tycho's hypotheses for precession are shown in Fig. 1. We are not concerned with Scaliger's ideas that the sidereal year is equal to the Julian year and that the pole of the equator will eventually reach Polaris, only that a motion of 

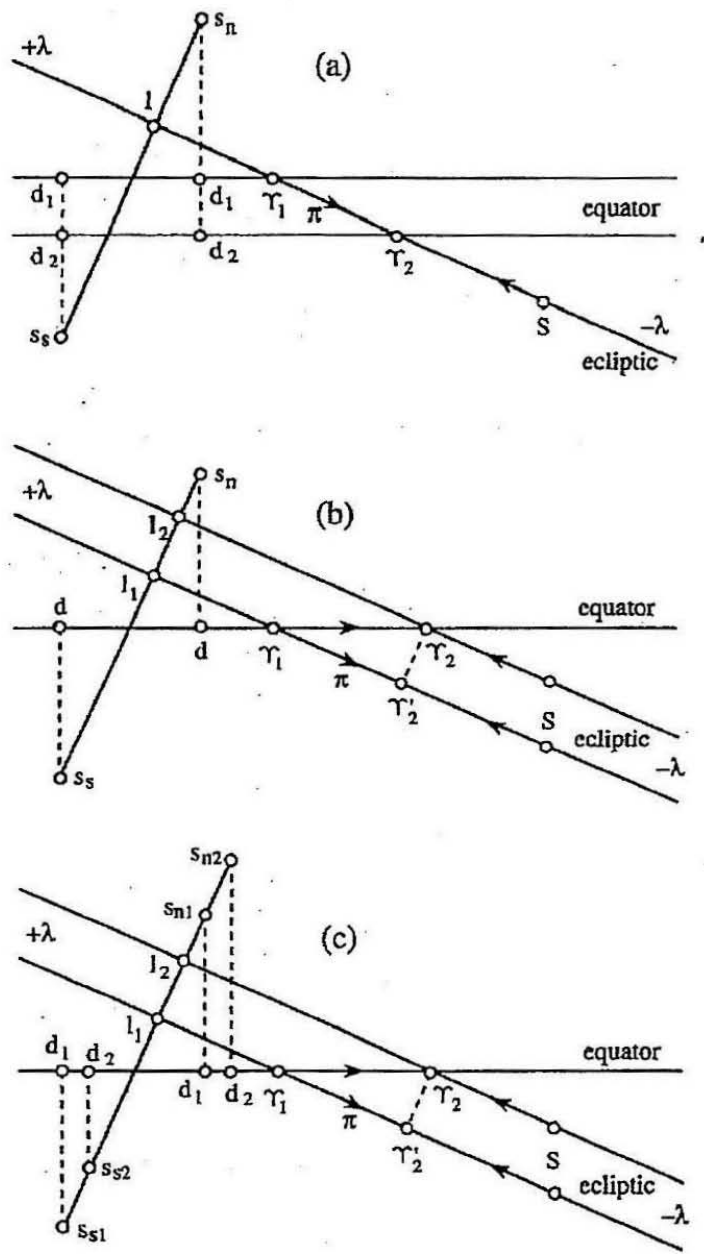

Fig. 1 Hypotheses for precession of the equinoxes according to (a) Scaliger, (b) Tycho, (c) correction of Tycho

the equator accounts for precession, which is shown in Fig. 1a. The Sun $S$ moves on the ecliptic in the direction of increasing longitude $+\lambda$ and initially crosses the equator at the vernal equinox $\gamma_{1}$; a northern star $s_{\mathrm{n}}$ and southern star $s_{\mathrm{s}}$ are shown with longitude $\lambda_{1}=r_{1} l$, latitudes $\beta_{\mathrm{n}}=s_{\mathrm{n}} l$ and $\beta_{\mathrm{s}}=s_{\mathrm{s}} l$, and declinations $\delta_{\mathrm{n}}=s_{\mathrm{n}} d_{\mathrm{l}}$ and $\delta_{s}=s_{\mathrm{s}} d_{1}$. Now after some time the pole of the equator has moved, shifting the equator so that the Sun crosses it at the vernal equinox $r_{2}$, and the precession of the equinox along the ecliptic is $\pi=r_{1} r_{2}$ in the direction of decreasing longitude $-\lambda$. 
The longitude of the stars has increased to $\lambda_{2}=r_{2} l=r_{1} l+\pi$, the latitudes have remained unchanged, and the declinations have changed, $s_{\mathrm{n}}$ increasing to $\delta_{\mathrm{n}}=s_{\mathrm{n}} d_{2}$ and $s_{\mathrm{s}}$ decreasing to $\delta_{\mathrm{s}}=s_{\mathrm{s}} d_{2}$. And if the pole of the equator has moved closer to the pole of the ecliptic-this motion is not shown in the figure-the inclination of the equator to the ecliptic has decreased, which also affects the declination but not the latitude of stars. All of this is just as it should be, and is essentially Copernicus's model but without the inequality and without the motion of the Earth. But if the axis of the Earth does not move, how is the equator shifted? Scaliger seems to think that the equator and its poles are located on a sphere, which moves in relation to the unmoving sphere of the fixed stars. This does raise a problem. If the sphere is inside the sphere of the fixed stars, it may move in this way, but a sphere with identical equator and poles, and with the identical motion, must still be located outside the sphere of the fixed stars to produce the diurnal rotation of the heavens parallel to the equator. If the sphere is only outside the sphere of the fixed stars and also produces the diurnal rotation, then it is difficult to consider the poles of the sphere of the fixed stars as not moving with respect to the poles of this outer sphere moving the equator. There is nothing wrong with that, and it is a way of transferring Copernicus's model for precession to the heavens, but one can hardly then say that the sphere of the fixed stars is absolutely at rest, of course aside from the daily rotation, which strictly, or usually, is required to have yet another sphere of its own.

Tycho's model for lunar latitude produces both a variation of the inclination of the lunar orbit to the ecliptic and a nonuniform regression of the nodes, and he believes that both can be applied to the Sun to produce the variation of the obliquity of the ecliptic and the nonuniform precession of the equinoxes. Tycho's model for the precession is shown in Fig. $1 \mathrm{~b}$, in which the Sun $S$ moves on the ecliptic, crossing the equator at $\gamma_{1}$, and stars $s_{\mathrm{n}}$ and $s_{\mathrm{s}}$ have the longitude $\lambda_{1}=\gamma_{1} l_{1}$, latitudes $\beta_{\mathrm{n}}=s_{\mathrm{n}} l_{1}$ and $\beta_{\mathrm{s}}=s_{\mathrm{s}} l_{1}$, and declinations $\delta_{\mathrm{n}}=s_{\mathrm{n}} d_{1}$ and $\delta_{\mathrm{s}}=s_{\mathrm{s}} d_{1}$. The Sun, as Tycho says, "describes one and another ecliptic in different ages, and moreover draws the intersections of the ecliptic with the equator backwards, and in fact not at all uniformly," so that after some time the Sun crosses the equator at $\Upsilon_{2}$, which is projected on to the previous position of the ecliptic at $\gamma_{2}^{\prime}$ in the direction of decreasing longitude $-\lambda$ by the precession $\pi=r_{1} r_{2}^{\prime}$, which may be nonuniform, as the regression of the nodes in the lunar model, and thus the period of the Sun's return to the equinox, the tropical year, may be nonuniform. Along with this nonuniform motion of the equinoxes, as in the lunar model, there is a variation in the inclination of the ecliptic to the equator, that is, a variation of the obliquity, which is not shown in the figure. So far, so good, but when we consider the effect on stars, there are problems. If the ecliptic moves and the sphere of the fixed stars does not move, then the longitude of stars increases to $\lambda_{2}=r_{2} l_{2}=r_{1} l_{1}+\pi$, which is correct. But the latitudes of stars also change, $s_{\mathrm{n}}$ reduced to $\beta_{\mathrm{n}}=s_{\mathrm{n}} l_{2}$ and $s_{\mathrm{s}}$ increased to $\beta_{\mathrm{s}}=s_{\mathrm{s}} l_{2}$, which is not correct and distinct from the change in latitude from the variation of the obliquity that Tycho has in mind; and the declinations do not change, which is also not correct. The solution to these difficulties, shown in Fig. 1c, is to make the fixed stars move with the ecliptic, so the latitudes $\beta_{\mathrm{n}}=s_{\mathrm{n} 2} l_{2}=s_{\mathrm{n} 1} l_{1}$ and $\beta_{\mathrm{s}}=s_{\mathrm{s} 2} l_{2}=s_{\mathrm{s} 1} l_{1}$ are unchanged, aside from the change produced by the variation of the obliquity, and 
the declinations are changed, from $\delta_{\mathrm{n}}=s_{\mathrm{n} 1} d_{1}$ to $\delta_{\mathrm{n}}=s_{\mathrm{n} 2} d_{2}$ and from $\delta_{\mathrm{s}}=s_{\mathrm{s} 1} d_{1}$ to $\delta_{\mathrm{s}}=s_{\mathrm{s} 2} d_{2}$. But that contradicts Tycho's belief that the fixed stars do not move and that the precession takes place, not by the advance of the eighth sphere, but by the precession of the equinoxes, which is the reason for applying his model for lunar latitude to the precession. Tycho would surely have discovered these difficulties had he worked out his model for the precession more carefully, but he did not do so, and all we have is this suggestion of applying the model for lunar latitude to account for a nonuniform precession and change of obliquity, which clearly fails.

Tycho's solar and precession theories, like so much he intended to do, were left unfinished. Both were established for about two hundred years before and after his own time, as shown by the tables in the Progymnasmata, and he clearly stated in that work and the letters to Scaliger that the consideration of long-period variations is deferred for his universal hypothesis of the Sun and complete restoration of astronomy. We have seen that in finding the length of the sidereal year, he applies Ptolemy's precession of $36^{\prime \prime}$ per year to Ptolemy's observations even though in establishing his own rate of $51^{\prime \prime}$ per year he shows that it applies not only to his own time, but is supported, more or less, by observations since antiquity. There would appear to be a contradiction, but Tycho does not see it that way, instead, perhaps, taking $51^{\prime \prime}$ per year as close to a mean value over a long period, subject to an inequality of magnitude and period not yet known. He also accepts, at least as more or less correct, Ptolemy's eccentricity and direction of the apogee, also used to find the length of the sidereal year, and length of the tropical year for the period between Hipparchus and Ptolemy, and he believes the obliquity varies over a range of about $20^{\prime}$, meaning that he accepts something close to Ptolemy's large obliquity of $23 ; 51,20^{\circ}$ in antiquity, nearly $20^{\prime}$ greater than his own $23 ; 31,30^{\circ}$. He was cautious about doubting the observations and parameters of his predecessors, except for Copernicus close to his own time, and while admitting the possibility of errors by Hipparchus and Ptolemy, did not consider their errors as large as his own parameters would suggest, believing instead that their observations could not be seriously inaccurate and there had to be changes of some kind in parameters over so long a period.

Scaliger had pointed out (8.85), correctly, that some of Hipparchus's equinoxes were in error by a quarter of a day, as shown in Almagest 3.1, and accused Ptolemy of errors of an entire day, which we know also to be true. Tycho's answer is more cautious (8.101-02). He admits that because Hipparchus's instruments were not graduated to single minutes, but only to twelfths of a degree, and because of neglect of solar parallax and refraction, errors of six hours in times of equinoxes were possible, and further, that Ptolemy's observations have even less certainty. But he will not say that there was an error of an entire day in the entries into Ptolemy's equinoxes, for this would require admitting an error in the declination of the Sun of about fivetwelfths of a degree, which the size and precision of the instruments, by which the interval between the tropics or the obliquity of the ecliptic was investigated within one-third of a minute (unless he also borrowed this from Hipparchus), does not allow. The reasoning here is that since Ptolemy states the obliquity as $23 ; 51,20^{\circ}$, to a precision of $\frac{1^{\prime}}{3}$, he could not possibly be in error by $25^{\prime}$, the daily change in 
declination of the Sun around equinox, so the equinoxes could not be in error by a full day. He also points out that the maximum latitude of the Moon of $5^{\circ}$, found by Ptolemy with parallactic rulers, does not show so great an error of the instrument, meaning close to $25^{\prime}$. Since so much depends upon the times of these equinoxes, as they are used to find the length of the tropical year, the eccentricity and direction of the apsidal line, the mean motion in longitude and epoch, and indirectly the longitudes of stars from which the rate of precession is found, that is, all the parameters which show long-period variation except the obliquity of the ecliptic, which depends upon altitudes of solstices, the absence of serious errors in the observations shows an absence of serious errors in the parameters. And a variation of $20^{\prime}$ in the obliquity is also accepted. Thus a variation of parameters over a long period must be taken seriously and accounted for by the universal hypothesis of the Sun in the complete restoration of astronomy, and that is what Tycho intended to do. Of course he did not do it, and it is not possible to know how or whether he would have changed his mind in attempting to do so. He, or an assistant to whom he assigned the work, would presumably have caught the error of applying the lunar latitude model to account for the nonuniform precession, at least as described in the letter to Scaliger, but more than this we cannot say. We may only conclude that he took the long-period variation of parameters in solar theory following from Ptolemy's observations, including the precession and obliquity as part of solar theory, as seriously as Copernicus did in his theory of the motions of the Earth. So although Tycho did not believe Copernicus had described these variations correctly or accurately, he was of the same mind as Copernicus with regard to the effects, although not the cause.

\section{Christian Longomontanus}

Christian Severinus Longomontanus (1562-1647) was Tycho's loyal and capable assistant for nearly ten years at Uraniborg, and was with him for part of his travels in Germany and then in Benatky and Prague. His last contribution while with Tycho was the final form of Tycho's lunar theory published in the Progymnasmata, most of which was Longomontanus's work, not always with Tycho's complete approval. He later became professor of mathematics at Copenhagen. His principal work, Astronomia Danica, published in 1622, was intended as a complete exposition of astronomy based upon Tycho's methods and observations, including the theory of the planets that Tycho did not live to complete, or even begin. Although no longer well known or much studied, since the contemporary work of Kepler made nearly everything in it obsolete, or about to be obsolete, it was regarded well enough in its day to be reprinted in 1640 . The work is in two parts, the first on spherical astronomy, the second, of concern here, on the Sun, Moon, planets, and stars, and there is an appendix on temporary phenomena of the heavens, new stars and comets. The title of the second part is "Theories of the motions of the planets in accordance with the observations of Tycho Brahe, and in fact his very own, re-established in a threefold form." The "three-fold form" means that everything is set out in Ptolemaic, Copernican, and Tychonic form, which Longomontanus prefers although giving 
the diurnal rotation, precession, and variation of obliquity to the Earth rather than the heavens, which are absolutely at rest. In making use of ancient observations, he does not take them as recorded by Ptolemy, as Copernicus did, but subjects them to examination and correction, as Tycho intended to do, and he considers his work to apply to all times, again as Tycho intended in his complete restoration of astronomy. This is specifically stated in the separate title page of Part Two, which is worth quoting: "The second part of Danish Astronomy, including the theories of the planets restored in two books, of which the former, after a description and comparison of the three-fold hypothesis of the world, namely, the ancient Ptolemaic, the astonishing Copernican, the modern of Tycho Brahe, treats the apparent motions of the fixed stars, likewise of the Sun and Moon in the same way, re-established and adapted to all ages of the world, together with the entire theory of eclipses and besides this a special treatment of the Moon; the latter treats the motions of the other five planets, on the basis of the three-fold hypothesis, similarly restored to the appearances of the heavens in the same way."

Although Tycho did not carry out his intended investigation of the motion of the Sun for all times, that is just what Longomontanus does in a lengthy history of solar observations and theory from antiquity to Tycho (28-49). Much of it does not meet with his approval, but he is also interested in explaining why things went wrong. $\mathrm{He}$ is, to say the least, direct in his evaluation (29).

For although the proof of the perpetual constancy of the celestial phenomena of the single motion of the Sun is evident, yet if the observations and likewise theories of each of the astronomers are to be believed, in none other do I find more disgraceful inconstancy, and this not only concerning the measure of the annual revolution of the Sun, but also the change of its eccentricity (as it is called) and the location of its apogee. Thus, it was determined by Ptolemy in his demonstration of the hypothesis of the Sun, and proved by observations of some kind, that in the nearly 300 years between Hipparchus and Ptolemy they were without any change, but soon after in the course of the following centuries they appear to be subject to inordinate change. Considering the causes of this more carefully, I perceive that none belong to the absolutely simple motion of the divine star, but all fault is deservedly to be ascribed to the astronomers, whose records of the motion of the Sun in different ages, as they maintain derived from the heavens, have been transmitted to posterity, in which records the motion of the Sun is more or less erroneous in one way or another from rather obvious causes. This disgraceful situation continued until the beginning of the more accurate restoring of astronomy was divinely granted to our age and to our Atlas, Tycho Brahe, the celestial observations of whom alone, both because of the correct and careful preparation of instruments as well as skill in observing, exclude all sensible error, as I, who was a student of Brahe's astronomy for ten continuous years, can perhaps be the best witness. But since, as we know, equal care had by no means been shown by his predecessors, therefore it is no wonder that with the progress of time, very abundant error emerged, in other bodies, but especially in the Sun. 
Longomontanus is suspicious of all early observations taken from declinations of the Sun, of equinoxes, where the daily change in declination is greatest, because of the insufficient size or skill in manufacture of instruments, incorrectly assumed latitude of the observer, and the effects of parallax and refraction. And the problems are worse for intermediate places where the daily change of declination is sensibly smaller, until the solstitial points where the location of the Sun cannot be obtained from observations because its declination remains invariable for many days. He believes that the length of the tropical year was obtained, not from such observations, but from cycles and syzygies of the luminaries, the Sun and Moon (30). All before Hipparchus believed the year to be $365 \frac{1}{4}$ days, as appears in the institution of the Olympiad, beginning anew in the fourth year near the rising of Sirius, and likewise other times of the year were recognized by the rising and setting of fixed stars, the custom of the most ancient Hesiod and later the Greeks and Romans. While all the observations of the Sun, which without doubt existed in Babylon and Egypt during the rule of the Assyrians, have perished, first a certain Meton of Athens, who flourished 430 years before the birth of Christ, also by use of the common length of the year $365 \frac{1}{4}$ days, a Julian year, estimated the mean periods (simplices cursus) of the luminaries, not so much with respect to the equinoctial and solstitial points, as to new Moons in his interval of 19 years, with a notable error which in the course of time to Hipparchus was found to be 5 days by the same Hipparchus- - but to the correction of Callippus, instituted six years before the death of Alexander, within four of his (Meton's) periods, which contained 76 single years, an anticipation of one day was observed in the new Moon-that is, in an interval of 304 years, or somewhat shorter, 300 years, as Scaliger says, just as the following words ascribed by Ptolemy to Hipparchus make clear. He then quotes Scaliger's quotation of Ptolemy's paraphrase and quotation in Almagest 3.1 from Hipparchus's book "On intercalary months and days" that according to Meton and Euctemon the years is $365 \frac{1}{4}$ days, ${ }^{12}$ and that Hipparchus says he finds as many months in 19 years as they did, but the year less than the quarter day by $1 / 300$ day, and thus in 300 years lacking five days from the years of Meton but only one day from the years of Callippus. He next paraphrases Copernicus's account in De revolutionibus 4.4, and explains everything at rather great length. Thus, Meton took the length of the year in the cycle of 19 years equal to 235 months to be $365 \frac{1}{4}$ days, as did Callippus, who deducted one day in four cycles of 76 years equal to 940 months from observing an eclipse of the Moon six years before the death of Alexander. (There is obviously a contradiction if both took the year to be $365 \frac{1}{4}$ days.) Hipparchus then corrected four cycles of Callippus, 304 years equal to 3760 months, by removing one day, and thus five days from Meton, so that, subtracting one day in 304 years, or shorter, in 300 years, he made the tropical year $365 \frac{1}{4}$ days reduced by $1 / 300$ day, that is $0 ; 4,48^{\text {h }}$, so the time is judged to be $365^{\mathrm{d}} 5 ; 55,12^{\mathrm{h}}$. His conclusion is striking (31).

And thus Hipparchus, together with his predecessors, attempted to hunt two hares with one leap, that is, to restore the new Moons within a certain interval of years and determine the individual periods from the mean motions of the luminaries, and at the same time to measure the annual revolution. Since, 
however, one does not at all depend upon the other in this way, he obtained a measure of the solar year, not, as it appears, from heaven or the Sun itself, but from certain syzygies of the luminaries, incorrect and in fact excessive in length. Unfortunately, Ptolemy chose to copy this error of Hipparchus rather than repudiate his opinion, so that this lunar cycle was also pleasing to him. What other evidence Ptolemy presents from Hipparchus for this assertion proves nothing since, as we proved earlier, the tropical or solstitial points were unobservable by the ancients, and moreover, the Hipparchan equinoxes notably oppose this opinion of Ptolemy (ipsius), as we shall soon demonstrate from Hipparchus's (ipsius) very observations. And we have treated these things at length so that men of our time will finally learn that the ancient astronomers, Hipparchus especially and Ptolemy, have been exposed in errors by reason of fairly obvious causes in assigning the period of the Sun.

This is, to say the least, strong language. Yet, although there is some confusion in Longomontanus's account, as the length of the year according to Meton, his principal point, that the tropical year of Hipparchus and Ptolemy was derived from a luni-solar cycle rather than from observations of the Sun alone is undoubtedly correct. ${ }^{13}$ Very briefly, the length of the Callippic Cycle of 76 years $=940$ months is $76 \cdot 365 \frac{1}{4}^{d}=27,759^{d}$. But Hipparchus had himself confirmed the Babylonian System B mean synodic month of $29 ; 31,50,8,20^{\mathrm{d}}$, from which 940 months are equal to $940 \cdot 29 ; 31,50,8,20^{d}=27,758 ; 45,30,33,20^{d}$, less than the Callippic Cycle by about $0 ; 15^{d}$, one-quarter day. Hence, in four Callippic Cycles, 304 years $=3760$ months, called the Hipparchan Cycle, one day must be subtracted, and the length of the cycle is $4 \cdot 27,759^{d}-1^{d}=111,035^{d}$. The length of the tropical year is thus $111,035^{\mathrm{d}} / 304=365 ; 14,48,9,28 \ldots$, which was rounded to $365 ; 14,48^{d}=365 \frac{1}{4}^{d}-\frac{1}{300}^{d}$. Hipparchus confirmed this year as well as he could from earlier observations of solstices, which is all he had, of which Ptolemy gives one example: the summer solstice observed by Aristarchus at the end of the fiftieth year of the first Callippic Period $(-279)$ and by Hipparchus at the end of the forty-third year of the third Callippic Period $(-134)$, an interval of 145 years in which the number of days was less than $145 \cdot 365 \frac{1}{4}^{\mathrm{d}}$ by one-half day, or one day in 290 years, close enough to 300 years to confirm a tropical year of $365 \frac{1}{4} \mathrm{~d}-\frac{1}{300} \mathrm{~d}$. Ptolemy's confirmation uses pairs of equinoxes of Hipparchus and his own, autumnal (5) and (12), vernal (6) and (13), each pair separated by 285 years $=15 \cdot 19$ years, surely no coincidence, which Longomontanus may have noticed although he does not mention it. The tropical year of Hipparchus, and later of Ptolemy, thus rests upon the application of the Babylonian System B month to the cycle 19 years $=235$ months, or 76 years $=940$ months, multiplied to an integer number of days, 304 years $=3760$ months $\approx 111,035$ days, and an approximate confirmation from independent observation of the Sun.

What Longomontanus does next is to set out nine of Hipparchus's equinoxes, six autumnal and three vernal, dated to the Era of the Death of Alexander ( -323 Nov 12, here EA, also called Era Phillip), and subject them to an "examination," or rather criticism (32). He believes the observations were made in Alexandria, not 
Rhodes, and that the equinoxes were found, not by interpolating between meridian altitudes of the Sun, but by an equatorial ring, so the stated times were directly observed - this is curious since two of the times are midnight-and it is no wonder, he says, that Hipparchus reached a precision of only one-quarter day. Further, the reported times of most cannot be accepted because they were at sunrise or sunset where the effect of refraction in the horizon makes the autumnal later and the vernal earlier by over half a day at the least, although in part reduced by neglect of the parallax of the Sun. Thus, as we shall see, when using two equinoxes observed at dawn, $6 \mathrm{AM}$, he corrects for refraction: from the autumnal equinox (7) of $-145 \mathrm{Sep}$ 27 he subtracts five hours, and to the vernal equinox (6) of -145 Mar 24 he adds five hours, from dawn to one hour before noon, the time Ptolemy reports the equinox was observed by a ring in Alexandria. He then computes that the year derived directly from various intervals between the equinoxes does not exceed 365 days by $5 ; 55,12^{\mathrm{h}}$, but from the autumnal equinoxes by not more than $5 ; 4^{\mathrm{h}}$ and from the vernal equinoxes by not more than $5 ; 43^{\mathrm{h}}$, with a mean of only $5 ; 24^{\mathrm{h}}$, deficient from $5 ; 55^{\mathrm{h}}$ by $0 ; 31^{\mathrm{h}}$. He notes that the parallax of the Sun in the equator at Alexandria, at an altitude of $59^{\circ}$, is $1 \frac{1}{2}{ }^{\prime}$, but does not use it to correct the times of the equinoxes near noon (by about $1 \frac{1}{2}$ ). Instead, he uses a curious computation for finding the intervals between equinoxes equivalent to the following: The interval between the autumnal equinox (4) of EA 167 Epagomenal 1 (-157 Sep 27) at noon and the vernal equinox (6) of EA $178 \mathrm{Mechir} 27$ ( $-145 \mathrm{Mar} 24$ ), with the correction of $+5^{\text {h }}$ from dawn to one hour before noon, is $4195^{\mathrm{d}} 23^{\mathrm{h}}$. But eleven years of $365^{\mathrm{d}} 5 ; 24^{\mathrm{h}}$ are $4017^{\mathrm{d}} 11 ; 40^{\mathrm{h}}$. The difference of $178^{\mathrm{d}} 11 ; 20^{\mathrm{h}}$ is the interval from the autumnal to the vernal equinox, which, subtracted from the year of $365^{\mathrm{d}} 5 ; 24^{\mathrm{h}}$ gives $186^{\mathrm{d}} 18 ; 4^{\mathrm{h}}$ from the vernal to the autumnal equinox. He makes one small mistake and finds the intervals $178^{\mathrm{d}} 11 ; 25^{\mathrm{h}}$ and $186^{\mathrm{d}} 17 ; 59^{\mathrm{h}}$, and notes that they differ, by several hours, from Ptolemy's intervals of $178^{\mathrm{d}} 6^{\mathrm{h}}$ and $187^{\mathrm{d}} 0^{\mathrm{h}}$. We have carried out everything precisely in accordance with the observations of Hipparchus, he says, not to show in them the truth itself, for neither the length of the tropical year nor the interval between the equinoxes which results is the truth, but so that it becomes clear how great are the errors in the observations of the ancients, lest we be so devoted and so bound to them that it will not be acceptable to change anything in them by applying the fair weighing of comparison.

Longomontanus is hard on Hipparchus, but he is harder still on Ptolemy (33).

We explained earlier what the intention of Ptolemy was concerning the measure of the tropical year, and, unless I am very mistaken in this conjecture, he observed both autumnal equinoxes at the very limit of the horizon-provided that they differ (as without doubt they do) from the number of those which occurred twice in one day due to the instrument, although in fact the instrument rested on one side or the other with respect to the horizons-which remarkably led to what he intended. And it is certainly worthy of notice that in these observations Ptolemy has so far adapted himself to the Hipparchan demonstration and hypothesis (constitutioni), of the measure of the tropical year as well as of the immutable eccentricity of the Sun, that for this very 
reason he did not assign his observations to the exact cardinal points of the days (i.e. sunrise, noon, sunset), but a little later, at one hour etc., so that you would judge (he did this) to give satisfaction to the Ptolemaic computation -rather than to heaven. But lest some astronomers to whom I write these things become indignant at our candor in investigating Ptolemy, prevailed upon by his ancient and exceedingly great authority, I ask that they consider what he relates elsewhere concerning the parallax of the Moon observed by him, and carefully compare (it) with our restoration which, to the best of my knowledge, in the lunar motion and distance corresponds exactly to the standard of heaven. And finally, let them notice in that passage (as I pass over others like it) Ptolemy reported from his observation the parallax of the Moon half a degree and more above the true parallax, for no other reason (as I believe) than that he pass off (obtruderet) upon posterity as genuine (pro legitima) that hypothesis of the Moon he previously established himself or, if you prefer, received from his predecessors, and only once confirmed by his computation. But now, I ask, what will be the prohibition (religio) from suspecting that here he was of the same intention, and relied upon those equinoctial observations of the Sun which served his purpose, but the others, of which it is very likely he made many more, he entirely concealed?

The remark about the instrument that showed two equinoxes in one day because it was out of alignment refers to Ptolemy's criticism of two bronze equatorial rings in Alexandria. So Ptolemy too, according to Longomontanus, followed Hipparchus in accepting the tropical year derived from the luni-solar cycle, as well as Hipparchus's eccentricity of the Sun, and adjusted his observations of equinoxes accordingly "to give satisfaction to the Ptolemaic computation rather than to heaven." This may be true, or one may say that like Hipparchus he took the year derived from the cycle to be correct in principle and confirmed it from observations of equinoxes, although we know not well since his own equinoxes are late by from 21 to 36 hours. In any case, it is evident that Longomontanus does not trust Ptolemy at all, as shown by the observation of lunar parallax he reported (Almagest 5.13), more than half a degree too large, and he suggests that Ptolemy's reason for this was pass off on posterity the defective hypothesis of the Moon that he invented or even received from his predecessors. Clearly, he does not approve of Ptolemy.

The examination of Ptolemy's equinoxes considers only one, the autumnal equinox (12) of EA 463 Athyr 9 at one hour after sunrise (139 Sep 26, 7 AM), which he believes was observed with an equatorial ring. Since the Sun was nearly in the horizon, the refraction in altitude was $32^{\prime}$, which in the horizon in Alexandria corresponds to about $32^{\prime}$ of longitude and 13 hours in time, all of which is about correct. And since refraction makes the autumnal equinox later, with correction for refraction the equinox occurred 13 hours earlier on Athyr 8 at 6 hours after noon (139 Sep 25, $6 \mathrm{PM}$ ). Then, the interval to the following vernal equinox (13), Pachon 7 at one hour after noon (140 Mar 22, 1 PM), taken here as exactly noon, is $178^{\mathrm{d}} 18^{\mathrm{h}}$-without the rounding, $178^{\mathrm{d}} 19^{\mathrm{h}}$-which Ptolemy and Hipparchus took as $178^{\mathrm{d}} 6^{\mathrm{h}}$ and the earlier correction of Hipparchus's interval $178^{\mathrm{d}} 11 ; 25^{\mathrm{h}}$. From the 
corrected time of Ptolemy's equinox, he computes the length of the tropical year between Hipparchus and Ptolemy (35). He takes Hipparchus's autumnal equinox (4) of EA 167 Epagomenal 1 at noon (-157 Sep 27, 12 PM) and Ptolemy's equinox (12) of EA 463, corrected by $-13^{\text {h }}$ to Athyr 8 at six hours after noon (139 Sep 25, $6 \mathrm{PM}$ ), and finds an interval in Egyptian years of $296^{\mathrm{ey}} 72^{\mathrm{d}} 6^{\mathrm{h}}$. In 296 Julian years, the addition of one-quarter day is $296 \cdot \frac{1}{4} \mathrm{~d}=74^{\mathrm{d}}$, exceeding $72^{\mathrm{d}} 6^{\mathrm{h}}$ by $1^{\mathrm{d}} 18^{\mathrm{h}}=42^{\mathrm{h}}$. The deficit in one year from $365 \frac{1}{4} \mathrm{~d}$ is thus $42^{\mathrm{h}} / 296=0 ; 8,30 \frac{4}{5} \mathrm{~h}$ and the length of the year $365^{\mathrm{d}} 5 ; 51,29 \frac{1}{5} \mathrm{~h}$, and from three pairs of equinoxes he finds it not greater and even a little smaller. Then the interval from the vernal to the autumnal equinox is $365^{\mathrm{d}} 5 ; 51,30^{\mathrm{h}}-178^{\mathrm{d}} 18^{\mathrm{h}}=186^{\mathrm{d}} 11 ; 51,30^{\mathrm{h}}$.

In addition to the equinoxes of Hipparchus and Ptolemy, Longomontanus also considers the equinoxes in the calendar of Julius Caesar, which he believes, following Pliny, was the work of Sosigenes, and which he finds in the agricultural calendar in Book 18 of Pliny's Natural History. These are definitely schematic, but so too are the intervals of Hipparchus and Ptolemy, from which they differ by one day, and the year of $365^{\mathrm{d}} 6^{\mathrm{h}}$ used for deriving the eccentricity, which is not the exact length of the year. In all, he now has four sets of intervals between the equinoxes, which we give with the length of the year in the following table.

\begin{tabular}{lllllll} 
Source & Year & \multicolumn{3}{c}{ Vern. to Aut. } & \multicolumn{2}{l}{ Aut. to Vern. } \\
Hipparchus-Ptolemy & $365^{\mathrm{d}}$ & $6^{\mathrm{h}}$ & $187^{\mathrm{d}}$ & $0^{\mathrm{h}}$ & $178^{\mathrm{d}}$ & $6^{\mathrm{h}}$ \\
Sosigenes & 365 & 6 & 186 & 0 & 179 & 6 \\
Hipparchus corrected & 365 & $5 ; 24$ & 186 & $17 ; 59$ & 178 & $11 ; 25$ \\
Ptolemy corrected & 365 & $5 ; 51,30$ & 186 & $11 ; 51,30$ & 178 & 18
\end{tabular}

For deriving a corrected eccentricity for the time of Hipparchus (36), since it is not possible to find the time of the solstice accurately, he uses the corrected interval between Ptolemy's vernal and autumnal equinoxes and an assumed longitude of the apogee near that found by Hipparchus, which makes for a very simple demonstration although it is set out a great length and computed to no less than seven places. We need not go through the steps, which have only the smallest inconsistencies. The interval from the vernal to the autumnal equinox of $186^{\mathrm{d}} 11 ; 51,30^{\mathrm{h}}$ gives a mean motion of $183 ; 49,12^{\circ}$, and taking the longitude of the apogee $\lambda_{\mathrm{A}}=$ Gemini $6^{\circ}$, where the radius of the eccentric $R=1$, the eccentricity $e=0.0364837$, and the maximum equation $c_{\mathrm{m}}=2 ; 5,26^{\circ}$. Hipparchus and Ptolemy found $\lambda_{\mathrm{A}}=$ Gemini $5 ; 30^{\circ}, e=0.0417$, and $c_{\mathrm{m}}=2 ; 23^{\circ}$. It then follows that the mean motion from the vernal equinox to the summer solstice is $93 ; 43,36^{\circ}$ and the interval of time $94^{\mathrm{d}} 2 ; 40^{\mathrm{h}}$, which he notes is about midway between Hipparchus and Ptolemy, $94^{\mathrm{d}} 12^{\mathrm{h}}$, and Sosigenes reported by Pliny, $93^{\mathrm{d}} 12^{\mathrm{h}}$, although somewhat closer to Hipparchus.

He then examines (37-47) the solar theories derived from the observations of al-Battānī, Walther, Copernicus, whose theory he corrects as he corrected Hipparchus and Ptolemy-Tycho had also corrected Copernicus's solar theory-and finally Tycho, finding that the maximum equations are all nearly the same, within 
$\pm 3^{\prime}$ of his own derivation of $c_{\mathrm{m}}=2 ; 4,48^{\circ}$, from $e=0.035714=1 / 28$, based upon his own small correction of Tycho's observations, so the eccentricity has remained constant, which shows that the eccentricity of Hipparchus and Ptolemy is erroneous and Copernicus's model for the variation of the eccentricity is incorrect. And that the eccentricity is equal to $1 / 28$, the divine unalterable proportion of the second number in the order of perfect numbers, equal to the sum of their factors, he takes as more evidence that Copernicus's variation of the eccentricity should be ignored. $\mathrm{He}$ also believes that the solar apogee has advanced with a uniform (sidereal) motion, from the beginning of Aries, with the Sun at the perigee at the beginning of Libra, at the Creation of the world- 5554 years before 1588 , thus $3967 \mathrm{BC}$ at the autumnal equinox-to $95 ; 30^{\circ}$ in 1588 at the time of Tycho. We shall take up his chronology below. He sets out a table comparing locations of the apogee from Hipparchus to Tycho with his own corrected locations, which depend upon his theory of precession yet to be explained, omitting Ptolemy as just plain wrong and correcting Copernicus, in which the greatest differences are $+37^{\prime}$ for Battānī and $-45^{\prime}$ for Copernicus, and concludes that Copernicus's variation of the direction of the apogee, which reaches $\pm 7 \frac{2}{5}^{\circ}$, is also incorrect. Indeed, he here cites the opinion of his friend Holger Rosenkrantz (48) that a variation of eccentricity of the Sun and the planets of the kind introduced by Copernicus is clearly contrary to the perpetual nature of the heavenly revolutions and is only derived from false principles, that is, from useless observations. ${ }^{14}$ Finally (48-49), from Hipparchus's vernal equinox (6) of -145 Mar 24 corrected by +5 hours, and Tycho's equinox of $1587 \mathrm{Mar} 10$, with a preliminary correction for the inequality of precession, he finds the length of the tropical year $365^{\mathrm{d}} 5 ; 49,20^{\mathrm{h}}$ but prefers $365^{\mathrm{d}} 5 ; 49,30^{\text {h }}$ based upon his correction of observations of ancient lunar eclipses. However, this is not the final length of the tropical year that underlies his tables of the mean motion of the Sun, which requires a more careful investigation, including of the precession.

The precession is taken up in the section on the fixed stars (53-56), and it is not uniform, so neither is the tropical year. Tycho had derived a rate of precession of $51^{\prime \prime}$ per year for his own time directly from the difference of the tropical and sidereal year, and then showed that it is mostly confirmed by observations of stars extending as far back as Timocharis, although he left open the question of whether it is in fact variable. Longomontanus instead begins with the observations, but he first corrects them: Timocharis's of occultations $\beta$ Sco, $\eta$ Tau, and Spica by the Moon corrected by Tycho's and Longomontanus's lunar theory; Hipparchus's of Spica in finding its longitude from its declination (and some unspecified coordinate); Ptolemy's longitude of Regulus measured from the Moon on an armillary by Longomontanus's solar theory; Battāni’s longitude of Regulus by its distance from $\beta$ Sco in Tycho's catalogue. These corrections are not consistent, and all are also corrected to longitude from the mean equinox using the equation of the nonuniform precession yet to be explained. The corrections for Timocharis, Hipparchus, and Battāni are less than $0 ; 30^{\circ}$, but Ptolemy's longitude of Regulus is advanced by $+1 ; 23^{\circ}$ from Leo $2 ; 30^{\circ}$ to $3 ; 53^{\circ}$, of which $+1^{\circ}$ is from correcting Ptolemy's longitude of the Sun from the mean equinox and $+0 ; 20^{\circ}$ from solar refraction reduced by parallax. Tycho's 
longitudes of Regulus and Spica are corrected only by the equation of precession of $-0 ; 8^{\circ}$. From all these, and a number of computational errors, he finds motions of from $44^{\prime \prime}$ to $57^{\prime \prime}$ per year, and settles on $0 ; 0,49,45^{\circ / y}$ as the mean rate of precession, close to $0 ; 0,49,46^{\circ / y}$ between Hipparchus and Tycho (which correctly computed is $0 ; 0,49,30^{\circ}$ ). For the obliquity of the ecliptic, he says he has corrected what his predecessors found for solar parallax and finds it to vary from $23 ; 53^{\circ}$ in about the year 3600 of the Creation of the world $(-366)$ to about $23 ; 31^{\circ}$ in the year 5400 of the world (1434), with the mean of $23 ; 42^{\circ}$, although the exact range is subject to a "perfect" criterion, as we shall see. Still, he is close to Copernicus, whose range is $23 ; 52^{\circ}$ to $23 ; 28^{\circ}$ with a mean of $23 ; 40^{\circ}$.

Before considering the precession, we must say something of Longomontanus's chronology and epochs $(47,57-58)$. He says that earlier astronomers have used various epochs for mean motions, as the Olympiad, Nabonassar, Alexander, Caesar, and the Incarnation, but for we Christians, two beginnings ought to be especially distinguished before the others: first when this most beautiful theater of the world began to exist by the word of omnipotent God, second when the only-begotten Son of God himself took on our human flesh and deigned to be born to restore the fallen world and liberate us from the power of the devil and eternal death. He acknowledges that the years and the time of year of both epochs are disputed by chronologers, but this dissension does not involve the celestial motions in any difficulty since they can properly be derived from other intervals securely confirmed by celestial observation. The point is that astronomical chronology can correct historical chronology. From the Creation of the world to the passion of the Son of God on the cross, and through him the salvation of the world, there elapsed 4000 solar years less one-half year. Since the age of Christ was then about $33 \frac{1}{2}$ years, the crucifixion was in AD 34 near the time of the vernal equinox and the Creation in $34-\left(4000-\frac{1}{2}\right)=-3966$ near the time of the autumnal equinox, that is, $3967 \mathrm{BC}$ at the autumnal equinox. At this time, the apogee of the Sun was at the beginning of Aries and the Sun at perigee at the beginning of Libra. Further, the obliquity of the ecliptic was then greatest, the precession of the equinoxes zero, and the inequality of the precession zero. In the tables of mean motion, however, the Era of the World is set later to -3963 Jan 1 at noon at Copenhagen. The reason is that this is the first year of a Julian cycle of four years with the leap year as the fourth year, as is the Era of Christ, AD 1 Jan 1 at noon, the other epoch of the tables, so both can be used with the same tables of collected and single Julian years. Although the date of the autumnal equinox of -3966 is not given, it can be computed from the solar tables and is -3966 Oct 24 at about $11 \mathrm{AM}$ in Copenhagen. ${ }^{15}$

There is a fine study of Longomontanus's model for the variable precession and obliquity (85-93) by Moesgaard (1975), and we have found it very helpful for our own exposition. In Fig. 2, the Earth is at $O$ and the pole of the mean ecliptic is at $\vec{E}$, about which the pole of the equator $N$ rotates, carrying with it the equator of the Earth and thus the celestial equator, which intersects the mean ecliptic with the mean obliquity $\tilde{\varepsilon}$. This is a conical motion of the axis of the Earth, causing the mean vernal equinox $\bar{\gamma}$ to precess along the mean ecliptic opposite to the order of the signs, from east to west, through the mean precession of $0 ; 0,49,45^{\circ / y}$ in a 


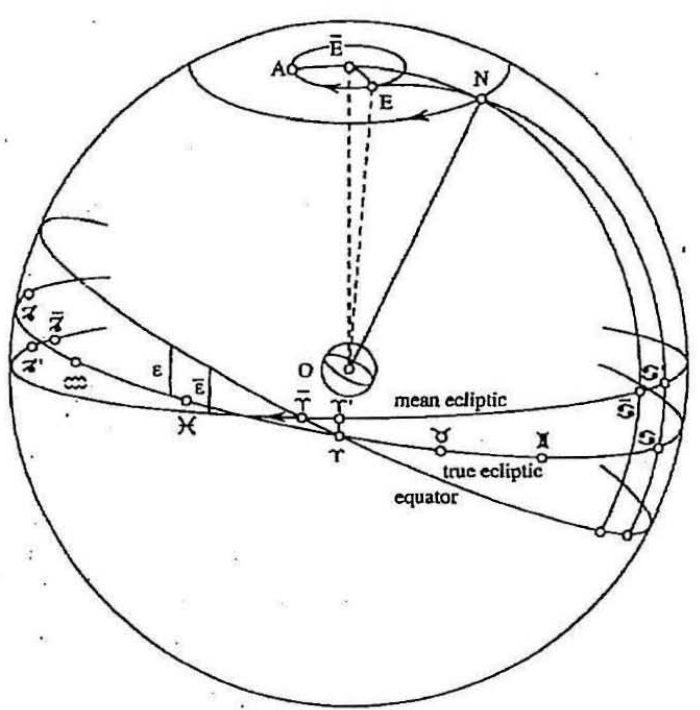

Fig. 2 Longomontanus. Hypothesis for precession of the equinoxes and variation of obliquity of the ecliptic

period of 26,050 years. Next, the pole of the true ecliptic $E$ rotates in the same direction measured from $A$ in a small circle about $\bar{E}$, causing a similar small circular motion of every point of the true ecliptic, the true path of the Sun around the Earth. ${ }^{16}$ The result is that the intersection of the equator and the true ecliptic, the true vernal equinox $r$, oscillates along the equator on either side of the mean equinox $\bar{r}$, and on the mean ecliptic there is a small inequality in the precession $c_{\mathrm{p}}=\bar{\gamma} \gamma \gamma^{\prime}$, which is zero when the pole of the true ecliptic is at $A$. The motion of the true ecliptic also causes the true obliquity of the ecliptic $\varepsilon$ to vary on either side of the mean obliquity $\bar{\varepsilon}$, with the maximum obliquity when the pole is at $A$, and the variation of the obliquity in turn causes the latitudes of stars to vary; the sphere of the fixed stars itself is absolutely at rest. The correction table gives the inequality of precession, variation of obliquity, and a proportional coefficient for the variation of latitude of stars, with the greatest variation at solstices, equal to the total range of the obliquity, decreasing to zero at equinoxes. The parameters are only slightly empirical. The range of the obliquity was given earlier as $23 ; 42^{\circ} \pm 0 ; 11^{\circ}$, but is now changed to $23 ; 42^{\circ} \pm 0 ; 10,53^{\circ}$. Why? Because $0 ; 10,53^{\circ} \approx 90^{\circ} / 496$, and 496 is the third in the order of perfect numbers. The maximum equation of precession, $c_{\mathrm{pm}}=\sin ^{-1}\left(\sin 0 ; 10,53^{\circ} / \sin 23 ; 42^{\circ}\right)=0 ; 27,5^{\circ}$, is merely derived from the variation of obliquity in the model. The period of the anomaly of precession and obliquity, of the motion of $E$, is 3600 years $=1,0,0$ years, a period considered significant since antiquity, so the anomaly is exactly $6^{\prime}$ per year, the first in the order of perfect numbers, although Longomontanus does not mention it. (These are Julian, not tropical or sidereal, years, which means that the model "knows" the Julian calendar. Copernicus's period of the anomaly of the obliquity is 3434 
Egyptian years and of precession half of that, 1717 Egyptian years.) At the Creation of the world, the mean precession is taken to be zero and the anomaly is zero, at $A$, so the inequality is zero and the obliquity is maximum. That all the parameters are determined by such criteria explains how Longomontanus can apply the equation of precession to longitudes of stars in order to find the mean rate of precession as he earlier did.

Longomontanus says that his model agrees well with the variation of obliquity, if Ptolemy is corrected to $23 ; 49^{\circ}$ for the effect of solar parallax at the solstices and Copernicus's $23 ; 28^{\circ}$ is in error as Tycho already showed. The only examples of precession, obliquity, and stellar longitude and latitude he computes are for the year 3000 of the world, $967 \mathrm{BC}, 82$ years after Hesiod flourished, and for the year 6000 of the world, sometimes taken as the year of the Second Coming, AD 2034, neither particularly helpful for empirical confirmation. But it is easy enough to compute the range of the variation of precession, which is minute, $0 ; 0,49,45^{\circ} \pm 0 ; 0,2,48^{\circ}$ per year or $1 ; 22,55^{\circ} \pm 0 ; 4,40^{\circ}$ per Julian century. Compare this with the Prutenic Tables, $0 ; 0,50,12^{\circ} \pm 0 ; 0,15,41^{\circ}$ per year or $1 ; 23,43^{\circ} \pm 0 ; 25,33^{\circ}$ per Julian century. Thus, the wide range of Copernicus's precession and the slow rate of Hipparchus and Ptolemy have been rejected entirely.

The determination of the refined length of the tropical year (94-96) is, to say the least, interesting. It is done by finding the intervals between pairs of vernal and autumnal equinoxes observed by Hipparchus and Tycho, taking the arithmetic mean of the deficits from integral Julian years, doing the same for equinoxes observed by Ptolemy and Tycho, again taking the mean of the deficits, and then taking the mean of both means. The result of the procedure is called limitata, which means bounded, placed within limits or accurately examined; the same term is used in Tycho's observational records for taking means and small adjustments, and it is possible that these too are the work of Longomontanus. ${ }^{17} \mathrm{He}$ first corrects for the solar inequality and the inequality of precession to find the time of the mean equinoxes unaffected by either.

The solar inequality is shown in Fig. 3, in which (a) is the configuration at the time of Hipparchus or Ptolemy and (b) at the time of Tycho; the difference is only in the longitude of the apogee $\lambda_{\mathrm{A}}$ as the eccentricity found by Longomontanus is invariable. The Earth is at $O$, from which the directions of the true equinoxes are $\gamma$ and $\Omega$, when the true longitudes are $0^{\circ}$ and $180^{\circ}$, and the center of the eccentric at $C$, from which the directions of the mean equinoxes are $\bar{\gamma}$ and $\bar{\Omega}$, when the mean longitudes are $0^{\circ}$ and $180^{\circ}$. This may be Longomontanus's own definition of mean equinox. The difference in direction is given by the solar equation $c$, which is the same at both equinoxes since the true distance of $r$ from apogee is $\lambda_{A}$ and of $\Omega$ is $180^{\circ}-\lambda_{A}$, for which the equations are equal and of opposite sign. The equations are computed from the true distance of the vernal equinox from apogee by $c=\sin ^{-1}\left(\sin e \sin \lambda_{\mathrm{A}}\right)$ where $e=1 / 28$ and $\lambda_{\mathrm{A}}$ is specific to the date of each observer; $c$ is positive at the vernal equinox, mean equinox after true equinox, and negative at the autumnal equinox, mean equinox before true equinox. He next adds the inequality of precession $c_{\mathrm{p}}$ to the solar equation $c$ and converts the sum $c+c_{\mathrm{p}}$, which is not given, to the interval of time $\Delta t$ between the mean and true equinox by dividing by the true hourly velocity of the Sun $\nu_{s}$, which is also not given, that is, 


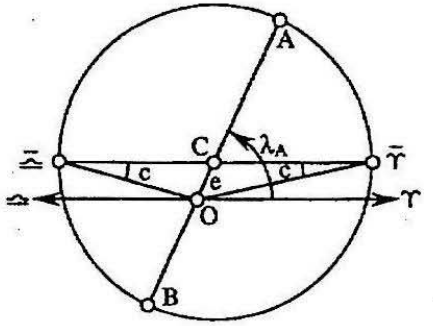

(a)

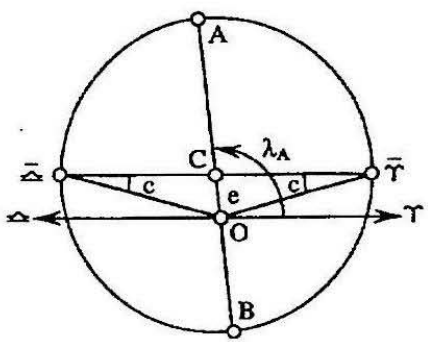

(b)

Fig. 3 Longomontanus. Determination of mean equinoxes at times of (a) Hipparchus and Ptolemy; (b) Tycho

$\Delta t=\left(c+c_{\mathrm{p}}\right) / \nu_{\mathrm{s}}$. The following table gives the observer, year of the equinoxes, $\lambda_{\mathrm{A}}$, $c, c_{\mathrm{p}}$, and for each equinox, vernal and autumnal, $c+c_{\mathrm{p}}$ and $\Delta t$.

\begin{tabular}{|c|c|c|c|c|c|c|c|c|}
\hline Observer & $\begin{array}{r}\text { Year } \\
-145\end{array}$ & $\begin{array}{c}\lambda_{\Lambda} \\
65 ; 30^{\circ}\end{array}$ & $\begin{array}{c}c \\
\pm 1 ; 51,44^{\circ}\end{array}$ & $\begin{array}{c}c_{\mathrm{p}} \\
-0 ; 10,12^{\circ}\end{array}$ & $\begin{array}{l}\text { Ver } c+c_{\mathrm{n}} \\
+1 ; 42,32^{\circ}\end{array}$ & $\begin{aligned} & \operatorname{Ver} \Delta t \\
+ & 1^{\mathrm{d}} 17 ; 50^{\mathrm{h}}\end{aligned}$ & $\begin{array}{l}\text { Aut } c+c_{p} \\
-2 ; 1,56^{\circ}\end{array}$ & $\begin{array}{c}\text { Aut } \Delta t \\
-2^{d} 0 ; 50^{h}\end{array}$ \\
\hline tolemy & $139 / 40$ & $70 ; 0$ & $\pm 1 ; 55,2$ & $-0 ; 21,0$ & $+1 ; 34,2$ & $+1 \quad 14 ; 45$ & $-2 ; 16,2$ & $-2 \quad 6 ; 45$ \\
\hline ycho & $1587 / 88$ & $95 ; 30$ & $\pm 2 ; 2,14$ & $+0 ; 7,12$ & $+2 ; 9,26$ & $4 ; 30$ & $-1 ; 55,2$ & $-122 ; 50$ \\
\hline
\end{tabular}

The interval $\Delta t$ is then added to the time of the true equinox to give time of the mean equinox. The equinoxes are paired such that each is the same year of a four-year Julian cycle, so the number of days in the interval of years is an integer. Hence, the difference $\Delta T$ of the calendar dates and times of the equinoxes is the deficit of the tropical years from an integral number of Julian years. The stated dates and times are from noon preceding by 12 hours the next Julian calendar date beginning at midnight. Hipparchus's vernal equinox (6) of $-145 \mathrm{Mar} 23$ at dawn is corrected for refraction by +5 hours, from $18^{\mathrm{h}}$ to $23^{\mathrm{h}}$, the time Ptolemy reports the ring in Alexandria showed this equinox, and his autumnal equinox (7) of -145 Sep 26 at dawn by -5 hours, from $18^{\mathrm{h}}$ to $13^{\mathrm{h}}$. Tycho's equinoxes were found by interpolation between meridian altitudes already corrected for parallax and refraction. The meridian of Alexandria (A) is adjusted to Uraniborg (U) by $-1 ; 35^{\mathrm{h}}$, as did Tycho. Here is a tabulation of the steps for the equinoxes of Hipparchus and Tycho:

\begin{tabular}{|c|c|c|c|c|c|}
\hline Observer & True Equinox & $t(\mathrm{~A})$ & $t(\mathrm{U})$ & $\Delta t\left(c+c_{p}\right)$ & Mean Equinox \\
\hline Hipparchus & $-14523 \mathrm{Mar}$ & $23^{h}$ & $21 ; 25^{\mathrm{h}}$ & $+1^{\mathrm{d}} 17 ; 50^{\mathrm{h}}$ & $25 \mathrm{Mar} 15 ; 15^{\mathrm{h}}$ \\
\hline Tycho & $158710 \mathrm{Mar}$ & - & $14 ; 56$ & $+2 \quad 4 ; 30$ & $12 \operatorname{Mar} 19 ; 26$ \\
\hline & & & & \multicolumn{2}{|c|}{$\Delta T 1732^{y}-12^{d} 19 ; 49^{h}$} \\
\hline Hipparchus & -14526 Sep & 13 & $11 ; 25$ & $-2^{\mathrm{d}} 0 ; 50^{\mathrm{h}}$ & $24 \operatorname{Sep} 10 ; 35^{h}$ \\
\hline Tycho & $158713 \mathrm{Sep}$ & - & $9 ; 26$ & $-122 ; 50$ & 11 Sep $10 ; 36$ \\
\hline
\end{tabular}

The arithmetic mean of the two deficits of $\Delta T$ from 1732 years is $12^{\mathrm{d}} 21 ; 54^{\mathrm{h}}$, and thus the deficit of the tropical year from the Julian year is $12^{\mathrm{d}} 21 ; 54^{\mathrm{h}} / 1732=$ 
$0 ; 10,44,8^{\text {h }}$. Now we do the same with equinoxes observed by Ptolemy and Tycho. Ptolemy's autumnal equinox (12) of 139 . Sep 25 at one hour after Sunrise is corrected for refraction by -13 hours, as Longomontanus showed earlier, from $19^{\text {h }}$ to $6^{\text {h }}$, but no correction is applied to the vernal equinox (13) of 140 Mar 22 since it is close to the meridian at an altitude where refraction is negligible.

\begin{tabular}{|c|c|c|c|c|c|c|}
\hline Observer & True & quinox & $t(\mathrm{~A})$ & $t(\mathrm{U})$ & $\Delta t\left(c+c_{p}\right)$ & Mean Equinox \\
\hline Ptolemy & 139 & $25 \mathrm{Sep}$ & $6^{\mathrm{h}}$ & $4 ; 25^{\mathrm{h}}$ & $-2^{\mathrm{d}} 6 ; 45^{\mathrm{h}}$ & $22 \operatorname{Sep} 21 ; 40^{\mathrm{h}}$ \\
\hline Tycho & 1587 & 13 Sep & - & $9 ; 26$ & $-122 ; 50$ & 11 Sep $10 ; 36$ \\
\hline Ptolemy & 140 & $22 \mathrm{Mar}$ & 1 & $\begin{array}{l}21 \mathrm{Mar} \\
23 ; 25^{\mathrm{h}}\end{array}$ & $+114 ; 45^{h}$ & $\begin{array}{l}48^{y}-11^{\mathrm{d}} 11 ; 4^{\mathrm{h}} \\
23 \operatorname{Mar} 14 ; 10^{\mathrm{h}}\end{array}$ \\
\hline Tycho & 1588 & 9 Mar & - & $20 ; 45$ & $+2 \quad 4 ; 30$ & $\begin{array}{c}12 \operatorname{Mar} 1 ; 15 \\
8^{\mathrm{y}}-11^{\mathrm{d}} 12 ; 55^{\mathrm{h}}\end{array}$ \\
\hline
\end{tabular}

Here the arithmetic mean of the two deficits of $\Delta T$ from 1448 years is $11^{\mathrm{d}} 11 ; 59$, $30^{\mathrm{h}} \approx 11^{\mathrm{d}} 12 ; 0^{\mathrm{h}}$, so the deficit of the tropical year from the Julian year is $11^{\mathrm{d}} 12 ; 0^{\mathrm{h}}$ / $1448=0 ; 11,26,11^{\mathrm{h}}$. Now we take the arithmetic mean of the two means just found:

Hipparchus-Tycho

Ptolemy-Tycho

Arithmetic mean

$$
\begin{aligned}
& 0 ; 10,44,8^{\mathrm{h}} \\
& 0 ; 11,26,11^{\mathrm{h}} \\
& 0 ; 11,5,9,30^{\mathrm{h}} \approx 0 ; 11,5,10^{\mathrm{h}}
\end{aligned}
$$

And since there is no sensible motion of the Sun in $0 ; 0,0,10^{\text {h }}$, we round to $0 ; 11,5^{\text {h }}$. The length of the tropical year is therefore $365^{\mathrm{d}} 6^{\mathrm{h}}-0 ; 11,5^{\mathrm{h}}=365^{\mathrm{d}} 5 ; 48$, $55^{\mathrm{h}}$. This exceeds Tycho's tropical year by ten seconds, and, for all of Longomontanus's trouble, is less accurate.

Since the mean precession is $0 ; 0,49,45^{\circ / y}$, the difference between the sidereal and tropical year, the time for the mean Sun to move through this arc, is $0 ; 0,49,45^{\circ} / 0 ; 2,28^{\circ / \mathrm{h}}=0 ; 20,10^{\mathrm{h}}$, although Longomontanus gives $0 ; 20,18 \frac{1}{3}^{\mathrm{h}}$, following very nearly from $0 ; 0,49,45^{\circ} / 0 ; 2,27^{\circ / \mathrm{h}}$ and not consistent with his own mean motion of the Sun; but the length of the sidereal year, $365^{\mathrm{d}} 5 ; 48,55^{\mathrm{h}}+0 ; 20,18 \frac{1}{3}^{\mathrm{h}}=$ $365^{\mathrm{d}} 6 ; 9,13 \frac{1}{3}^{\mathrm{h}}$, is, by luck, much better than Tycho's sidereal year. The variation in the length of the tropical year, determined by the annual change of the inequality of precession, is quite small. Since the greatest annual change is $\pm 0 ; 0,2,48^{\circ}$, which the mean Sun covers in $0 ; 0,2,48^{\circ} / 0 ; 2,28^{\circ / \mathrm{h}}=0 ; 1,8^{\mathrm{h}}$, the greatest variation of the tropical year is $365^{\mathrm{d}} 5 ; 48,55^{\mathrm{h}} \pm 0 ; 1,8^{\mathrm{h}}$, that is, the excess over 365 days is from $5 ; 47,47^{\mathrm{h}}$ to $5 ; 50,3^{\mathrm{h}}$; this contains $5 ; 49,16^{\mathrm{h}}$ of the Alfonsine and Prutenic Tables, but is far short of Ptolemy's 5;55,12 . Finally, in the tables of the mean motion of the Sun, from the difference of the mean motions in longitude and anomaly, the apogee has a tropical motion of $1 ; 42,59^{\circ}$ per Julian century or $0 ; 1,1,47^{\circ / y}$. Subtracting the mean precession of $0 ; 0,49,45^{\circ / y}$, the sidereal 
motion of the apogee is about $+12^{n / y}$ direct, differing notably from Tycho's $-6^{m / y}$ retrograde.

Longomontanus, as noted, attempted to do what Copernicus earlier attempted and Tycho intended, to derive a theory of the Sun, precession, and obliquity correct for all times. He believed himself to be highly critical of ancient observations and theory, and he was, which Copernicus was not, but he too had no choice but to use at least the observations, with corrections if necessary, in order to achieve his goal. His work is characterized by acute insights, as that Hipparchus's tropical year was derived from a luni-solar cycle rather than from observations of the Sun alone, which at best served for confirmation of the year derived from the cycle. But also wishful thinking, as the "perfect" parameters for solar theory, precession, and obliquity, even the model for precession itself, and carelessness, as his corrections and even selections of ancient observations; and his computations are all too often at least slightly inaccurate, as is also true in other parts of his work. Nevertheless, he does show that one can be aware of the problems of ancient observations, but attempt to correct and make use of them, and in this way he goes beyond what Copernicus did and what Tycho was willing to do. Had Tycho carried through his reform of astronomy for all ages, he too may have done much the same thing, but it is more likely that he would have done nothing and left the work to an assistant, Longomontanus if he returned to Tycho's service, or Kepler if he were willing to follow Tycho's orders. But when Kepler did address these problems, Tycho was long gone, and thus he pursued them in his own way, more ingeniously than Tycho but more cautiously than Longomontanus. It is to Kepler's investigations over a period of twenty years to which we now turn.

\section{Johannes Kepler}

Kepler was already concerned about the reliability of Ptolemy's observations when he wrote the Astronomia nova, the last two chapters of which (69-70) are devoted to attempting to correct them in order to establish accurate ancient positions of Mars for determining its mean motion and the motions of its aphelion and nodes. He assumes, reasonably, that Ptolemy observed Mars by measuring its distance from fixed stars with the armillary, although Ptolemy gives no details for the three oppositions, and only for his one observation outside of opposition does he give the distance from a star and the Moon. Since the armillary is aligned by setting it on the Sun or on a star, the longitude of which depends upon an earlier alignment on the Sun, it is necessary to investigate Ptolemy's solar theory. $\mathrm{He}$ is suspicious of Ptolemy's procedures for establishing solar theory, and is uncertain whether Ptolemy found the equinoxes using an equatorial ring or, as he would prefer, meridian altitudes. But he has determined that Ptolemy's equinoxes do not agree within a day and a half in comparison with earlier observations of Hipparchus and later observations of al-Battānī and Tycho, which all agree in the same uniformity from which Ptolemy's equinoxes alone depart. Thus, he has isolated the 
errors in Ptolemy's equinoxes by comparison with observations consistent with a uniform tropical year, and he specifically rejects models for a nonuniform precession, which would produce a nonuniform tropical year. But then he notes that if instrumental error made the vernal equinox late, meaning that the equator is placed too high, it would make the autumnal equinox early, and if two days were subtracted from the interval between the equinoxes, the eccentricity of the Sun would change greatly. And since Ptolemy left the eccentricity as great as Hipparchus found, we must believe that he correctly observed the time the Sun was at the beginning of Aries.

However, the constancy of the solar equations found in our age by Tycho, and about the same several centuries earlier by al-Battānī and az-Zarqaāl, 20' smaller than Hipparchus seems to have demonstrated for himself and Ptolemy retained, argues that the equations were the same in Ptolemy's age and his own equation in error. Since the equation is sensitive to small changes in the times of the observations, and the ancient observations, especially of the solstices, were not sufficiently accurate, we may use the modern equations to correct Ptolemy's equinoxes, not by over a day, but by correcting the time of day, making the vernal 8 (text: 3 ) hours later and the autumnal as many hours earlier, so that in both there was an error of $8^{\prime}$ in the declination of the Sun, for Ptolemy's instruments were surely graduated only to $10^{\prime} .^{18}$ And a change of a quarter of a day in the time of the solstice, which is easily possible because of its uncertainty, would produce a large change of $8^{\circ}$ in the direction of the apsidal line. Thus, we see that while Kepler recognizes the possibility of large errors in Ptolemy's equinoxes, like Tycho, he is not willing to believe that he could go so wrong, and instead makes smaller corrections by applying the modern eccentricity, which does show that he considers the eccentricity, as well as the tropical year, to be constant. He then attempts to correct Ptolemy's longitudes of Mars by making a variety of assumptions about the eccentricity and apsidal longitude of the Sun and the longitudes of the fixed stars, by which he means the observed longitude of Mars since its longitude was measured by setting the armillary on some star. The investigation of seven different cases is, to say the least, bewildering, and he finds that changes in the longitude of stars, that is, of Mars, make a greater difference than changes in the solar theory. He also examines, critically, Ptolemy's report of an occultation, or contact, of $\beta$ Scorpii by Mars on $-27118 \mathrm{Jan}$ at dawn, which he decides applies better to $\nu$ Scorpii, and the report by Aristotle in De caelo 2.12 of an occultation of Mars by the dark part of the half-Moon, which he dates to -356 4 May (the text reads 4 April). ${ }^{19}$

Although the investigation of Ptolemy's solar observations and theory is inconclusive, Kepler does take seriously the decrease of the obliquity of the ecliptic and the variation of the latitude of fixed stars. Tycho had found that, compared to the time of Ptolemy, for stars located near the solstices, near summer solstice latitudes of northern stars increased and of southern stars decreased, near winter solstice latitudes of northern stars decreased and of southern stars increased, and these variations diminished approaching the equinoxes, where there were no changes. In the correspondence with Scaliger, he accounted for both the decrease of the obliquity and the variation of the latitude of stars by a variation of the obliquity of the ecliptic 
over a range of about $20^{\prime}$ with respect to a fixed celestial equator and sphere of fixed stars, like the variation of the inclination of the Moon's orbit to the ecliptic in his lunar theory of about the same range and by essentially the same hypothesis. This would indeed produce both effects although, as we have noted, the shift of the equinoxes as the Sun crosses the equator at points moving successively westward, producing a rotation of the ecliptic along the equator corresponding to the regression of the nodes in the lunar theory, would also cause a second, unwanted and incorrect, variation in the latitude of stars.

Kepler's hypothesis to account for both the decrease of obliquity and the variation of latitude of stars is entirely different, and avoids the problems of Tycho's. It is part of his theory of planetary latitude, and also accounts for the change of extreme latitudes and regression of the nodes of Mars and, in principle, the other planets since Ptolemy (68) ${ }^{20}$ It consists of a rotation of the "true ecliptic," defined by the motion of the Earth about the Sun, not along the celestial equator, which causes the problems of Tycho's hypothesis, but along the "mean ecliptic," also called the "royal road" and "royal circle," defined by the plane of the equator of the rotating Sun. Although either direction is possible, he believes it more likely that the rotation takes place to the west, that is, the nodes and limits of the true ecliptic regress in longitude as do the lunar nodes and limits, but very slowly, with a period of many thousands of years. The effect on the latitude of stars is shown in Fig. 4, in which the mean ecliptic is in the equatorial plane of the Sun $S$ and the true ecliptic shifts from the position "ecl 1" to "ecl 2", shown by the westward shift of the nodal line $U \Omega$ from 1 to 2 . The nodal line is directed to the vicinity of the summer solstice $\sigma$ and winter solstice $\eta_{0}$, the limits are near the vernal equinox $\gamma$ and autumnal equinox $\Omega$,

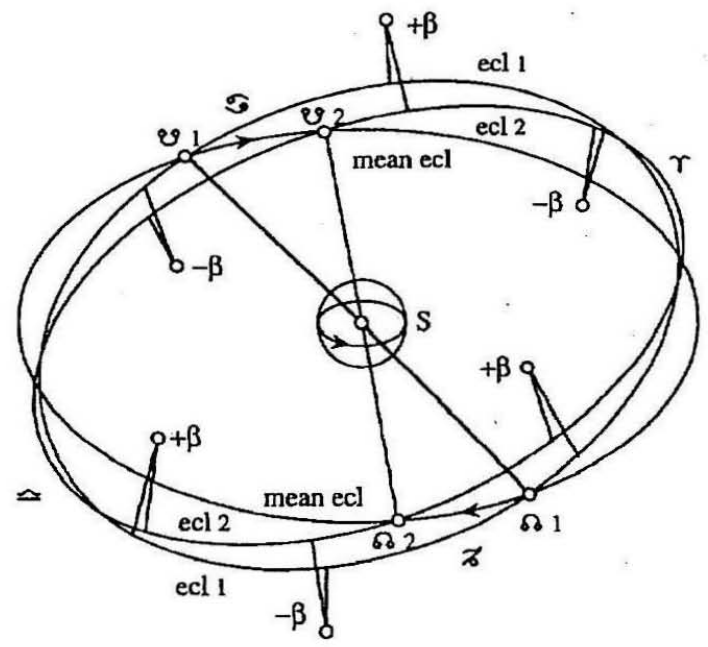

Fig. 4 Kepler. Rotation of true ecliptic to account for variation in latitude of stars 
although these locations will change slowly with time. As shown in the figure, the latitudes of northern stars $+\beta$ and southern stars $-\beta$ change as Tycho found near the solstices, the nodes, where the true ecliptic is most inclined to the mean ecliptic, and the changes are small or zero near the equinoxes, the limits, where the true ecliptic is parallel to the mean ecliptic. The very same motion of the true ecliptic accounts for the variation of the obliquity. According to Kepler, the reason for the decrease of the obliquity from $23 ; 51 \frac{1}{2}^{\circ}$ in antiquity to $23 ; 31 \frac{1}{2}^{\circ}$ at present, the range of $20^{\prime}$ recognized by Tycho, is that the Earth's equator holds a fixed inclination, not to the true, but to the mean ecliptic; consequently the inclination varies with respect to the moving true ecliptic, and this motion of the true ecliptic is also the cause of an inequality in the precession of the equinoxes. In Fig. 5, the initial intersections of the equator and true ecliptic, the equinoxes, are $\gamma_{1}$ and $\Omega_{1}$, and the solstices are $\sigma_{1}$ and $\eta_{0_{1}}$. As the nodal line $U$ ภ of the true ecliptic shifts westward from 1 to 2 , so do the true equinoxes to $r_{2}$ and $\Omega_{2}$ and the true solstices to $\sigma_{2}$ and $\eta_{2}$, although nonuniformly because of the obliquity of the true ecliptic, which the same motion causes to decrease from $\varepsilon_{1}$ to $\varepsilon_{2}$.

The theory is not worked out quantitatively or in detail, but it is clear that only an inequality of the precession could result, not the mean precession itself, which must be due to a motion of the Earth's axis, because, compared to the precession, the motion of the true ecliptic is very slow, according to Kepler's speculation, none other than the sidereal motion of the Earth's apsidal line, although he later decided that it is independent but still of very long period. Nevertheless, Kepler is on to something important and entirely original. Attributing the change in latitude of fixed stars and the decrease of the obliquity of the ecliptic to a rotation of the ecliptic, of - the Earth's orbit around the Sun, is essentially correct, although the rotation, produced by planetary perturbations, does not take place in a fixed plane of the solar equator and is more irregular. So while the (Newtonian) celestial mechanics of these motions is more complicated, Kepler here devised the first even remotely

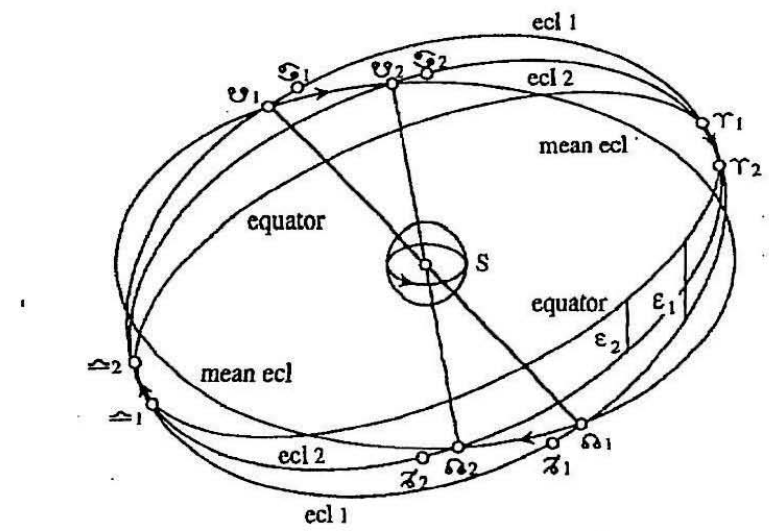

Fig. 5 Kepler. Rotation of true ecliptic to account for variation of obliquity of the ecliptic 
correct model for secular changes in the orbit of the Earth, and likewise of the other planets since such motions are not unique to the Earth.

In the Epitome of Copernican Astronomy 7, Kepler quantifies this model. In Fig. $6 \mathrm{a}, \bar{E}$ is the pole of the mean ecliptic, and thus of the solar equator, $E$ the pole of the true ecliptic, which moves about $\bar{E}$ in a small circle through $\vartheta$, and $N$ the pole of the celestial equator, which moves about $\bar{E}$ through the mean precession, both motions in the direction of decreasing longitude, from east to west. The motion of $E$ about $\bar{E}$ corresponds to the rotation of the true ecliptic in Figs. 4 and 5 , which show great circles a quadrant from the poles, and is a geometrical result of the physical causes moving the Earth about the Sun just as the motion of $N$ is a geometrical result of the precessional motion of the Earth's axis. Note that this differs from Longomontanus's model in Fig. 2, in which the motion of the pole of the true ecliptic $E$ in the small circle about the pole of the mean ecliptic $\bar{E}$ produces, not a rotation of the true ecliptic with respect to the mean ecliptic, but a motion of each point of the true ecliptic in a circle equal to the radius of the small circle. The mean obliquity $\bar{\varepsilon}=\bar{E} N=24 ; 17,40^{\circ}$ and the radius $r=\bar{E} E=1 ; 47,40^{\circ}$; hence the true obliquity $\varepsilon=E N$ varies from $22 ; 30^{\circ}$ to $26 ; 5,20^{\circ}$, a very wide range. This implies an inclination of the solar equator to the ecliptic of $1 ; 47,40^{\circ}$; correctly, as later found from the motion of Sunspots, it is $7 ; 15^{\circ}$. And the maximum equation of precession, where $\bar{E} N$ and $E N$ extended meet the true ecliptic (not shown), is $\sin ^{-1}(\cot \bar{\varepsilon} \sin r)=3 ; 58,45^{\circ}$ (corr. $3 ; 58,40^{\circ}$ ). But, Kepler says, half the period is more than 36,000 years, and $E$ was at $E_{0}$, with the obliquity at its mean value, "at the beginning of the world." When would this be? Although no date is given in the Epitome, in the 1621 edition of the Mysterium Cosmographicum (23) he takes the evening of 24 July $3993 \mathrm{BC}$ in Chaldea as the beginning of the second day, when God created the firmament. Thus, only about 5600 years have elapsed, and the pole of the true ecliptic has not moved all that far; in the Rudolphine Tables, from the Creation to 1600 the motion is less than $26^{\circ}$. and the entire period just over 77,758 years, far longer than the precession with a period of about 25,412 years. He notes that the ratio of the motion of the pole of the ecliptic $\vartheta$ to the motion of the pole of the world, the mean precession $\bar{\pi}$, is fairly precisely as $4 / 3$, a perfect fourth, although that is not mentioned, In fact it is the sum $(\bar{\pi}+\vartheta)) / \bar{\pi} \approx 4 / 3.01 \approx 4 / 3$.

The model described here is the second, "entirely archetypal," of no less than five for the variation of the obliquity and the inequality of precession in the Rudolphine Tables. Three are "mixed," partly archetypal and partly observational, for $\bar{\varepsilon}$ and $r$ and the periods and epochs of $\vartheta$. The first, based "entirely upon trust of the ancient observations," has a smaller range of the obliquity of $23 ; 28,28^{\circ}$ to $23 ; 53,16^{\circ}$, close to Copernicus's $23 ; 28^{\circ}$ to $23 ; 52^{\circ}$-from $\bar{\varepsilon}=23 ; 40,55^{\circ}$ and $r=0 ; 12,24^{\circ}$ - a maximum equation of precession of $0 ; 30,31^{\circ}$, and a period of just 2665 years. These numbers are not consistent, and there are other inconsistencies among the different methods, as computing the obliquity for motion of $E$ on the small circle, which is strictly correct, or for a libration on the diameter, as in Copernicus's model, in which it is the pole of the equator that librates. The libration, however, is intended only as a simpler, approximate computation as it would not produce the rotation of the true ecliptic that is essential to the model. Nevertheless, all the models show that 
(a)

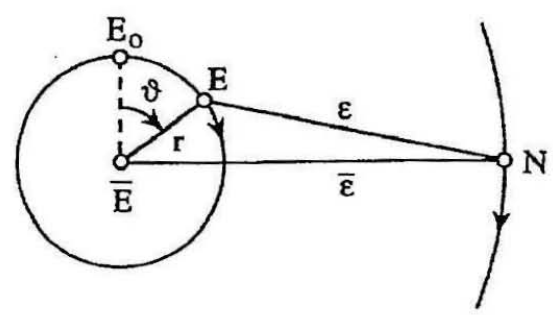

(b)

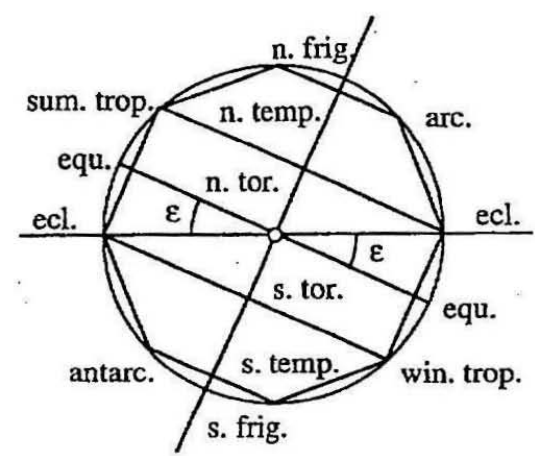

Fig. 6 Kepler. (a) Motions of the poles of the true ecliptic and equator about the pole of the mean ecliptic. (b) Climate zones of the earth at the minimum obliquity of the ecliptic

a variation of the obliquity and an inequality of precession are still a part of Kepler's astronomy.

In fact, Kepler established the "archetypal" variation of the obliquity from its consequences for climate zones of the Earth (Epitome 3.4), shown in Fig. 6b. With the minimum obliquity $\varepsilon=22 ; 30^{\circ}$, the Earth is divided by sides of an octagon subtending $2 \varepsilon=45^{\circ}$, that is, the torrid zone between the tropics subtends two sides, the two frigid zones beyond the arctic circles subtend two sides, and the two temperate zones in between subtend four sides, making eight sides of $45^{\circ}$. And at Creation, with the mean obliquity $\bar{\varepsilon}=24 ; 17,40^{\circ}$, the sum of the surface areas of the torrid and frigid zones equals the surface areas of the temperate zones. Considering a hemisphere on one side of the equator, the area of the torrid zone is as $\sin \bar{\varepsilon}=0.4114$, of the frigid zone as $1-\cos \bar{\varepsilon}=0.0886$; their sum is 0.5 and the remaining 0.5 from 1 is as the equal area of the temperate zone. Since the same relation holds for the other hemisphere, just as Kepler says, the sum of the areas of the torrid zone and two frigid zones equals the sum of the areas of the two temperate zones. Interestingly, this clever idea follows from Pappus's theorem (Collection 5.36), which Kepler also uses for summing the increments of libration in his physical planetary theory.

We have digressed from our principal subject of examinations of Ptolemy's solar observations and theory. In the Astronomia nova, Kepler recognized the possibility of large errors in the observations, but made only small corrections and substi- 
tuted the modern eccentricity and equation in the solar theory. Some years later, he decided that Ptolemy's equinoxes could not be corrected so easily, but remained uncertain about the cause of the errors. In a series of manuscript notes concerning the obliquity of the ecliptic, dates of equinoxes and solstices, and length of the tropical year, he considered evidence and reports from antiquity, in fact from Hercules, the founder of the Olympiads, who observed the solstices and equinoxes at eight degrees of their signs 1260 years before Christ, through Meton and Euctemon, Hipparchus and Ptolemy, al-Battānī and az-Zarqāl, to Regiomontanus, Walther, Copernicus, and Tycho. ${ }^{21}$ Like Longomontanus, he believes that Hipparchus and also Ptolemy observed the equinoxes with an armillary, so the stated times are those observed, not interpolated, and could be affected by refraction and misalignment of the instrument. There are two remarks we shall quote here. The first is (21.1.316): "Since Hipparchus varied so much (by quarter days) in the autumnal equinoxes, is it believable that Ptolemy found nothing clearly which differed from the Hipparchan computation? Or did Hipparchus reach his goal unknowing (caecus, blind), with fortune as his guide? Or should we rather believe Ptolemy favorable to Hipparchus through trust in the observations, namely, (because) something of Pythagorean philosophy lay hidden in the mystic numbers $94 ; 30,92 ; 30,178 ; 15$ (in margin: 378, $370,713)$ ? I note also that the year does not so precisely fill this number of hours." That the intervals in days between the equinoxes and solstices, multiplied to integers (of quarter-days) in the margin, are based upon Pythagorean philosophy can hardly be taken seriously, and Kepler poses it only as a question (to which the answer is surely no). The second remark is one that has defined the problem of Ptolemy's equinoxes to this day (21.1.324): "It therefore remains that either Ptolemy committed fraud with fabricated observations, or from a kind of awe and reverence for the ancients preferred to confirm rather than refute them, neither of which is likely in the philosopher Ptolemy, a defender of candor and truth, as is witnessed by many judgments (gnomis), especially since he could expect no advantage or fame from this, but rather greater advantage and fame from correcting the ancients. But that he was not obsequious to the ancients, he left witnessed in many ways, refuting Hipparchus where it was required. Therefore in fact the year was longer." This last appears to hold that the observations were correct and the year in fact longer, but is probably just speculation and not an opinion Kepler held.

In the Epitome of Copernican Astronomy 7, he is more certain of the error in the equinoxes. He notes (7.523) that in the eleven or twelve centuries since Proclus, the equinoctial points have precessed at a uniform rate, in which the observations of Hipparchus and Timocharis also agree for eighteen centuries "if you disregard Ptolemy alone." "Therefore, if something happened to the axis of the Earth by which it moved irregularly away from its proper position, it occurred between Hipparchus and Ptolemy, in an interval shorter than 300 years, and it was restored to its former state between Ptolemy and Proclus, again in an interval of three centuries. Therefore, not unjustly can there be doubt concerning Ptolemy's observations of the equinoxes." He also notes (7.527) that Hipparchus determined the length of 300 years by omitting one day in four Callippic Cycles of 304 years, the same explanation given by Longomontanus and, as it appears here, perhaps originally by 
Tycho. "Ptolemy retained this opinion of Hipparchus, much too carelessly, as was evident to Tycho Brahe, even though Ptolemy himself appeared to prove it with his observations. For immediately after Ptolemy, it (the length of the year) was found to lose one day far more rapidly (than in 300 years). And thus if we disregard Ptolemy alone, a uniform reckoning (of the year) will be consistent from Hipparchus, through Proclus, al-Battānī, Persians, Arabs, Jews, Germans, up to our own time, which makes the equinoxes earlier by one day in 134 years, 3 days in 400 years, as the regulation of the Gregorian civil year represents very nearly."

He now has a new speculation for the cause of Ptolemy's errors, which we give in the question and answer form of the Epitome (7.523-24).

Is it possible that Ptolemy was in error concerning the observation of the correct day of the equinox, and in what way?

He was not in error in the altitude of the pole, as this is confirmed by many proofs, nor in the altitude of the Sun as this depends upon the altitude of the pole. Perhaps, therefore, what follows happened to him, that since under Augustus the observation of the Egyptian year was abolished, Ptolemy sought the day of the Egyptian year through the Moon if he was concerned with the Moon, or through the Sun and its calculation handed down by Hipparchus if he was concerned with observation of the Sun; then neglecting agreement with observations of the Moon and trusting too much in the calculation of Hipparchis, he thought to himself that it was only necessary to be concerned about the hour of the entry into Aries. For Ptolemy could not trust the Roman calendar, which was necessarily observed in Egypt, because even after the correction of Augustus, at some time on the authority of the priests one day was omitted from the year and restored in the following year.

The point here is that because of arbitrary omissions and restorations by the priests in the Roman calendar, in use in Egypt since introduced by Augustus, and even after Augustus's correction of the initial errors of intercalation following the Julian reform (three incorrect additional leap years, compensated by making three following leap years common years), Ptolemy would use the computation of the Moon or Hipparchus's computation of the Sun to determine the date of an observation in the Egyptian year. Thus, he would determine only the hour of an equinox by observation and trust Hipparchus's solar theory to determine the day, since he could not believe it to be in error by a full day, and then fail to check the position of the Moon, which would immediately show the error of one day since the Moon moves about $13^{\circ}$ per day. This ingenious explanation would then account for the errors in the dates of Ptolemy's equinoxes without accusing him of fabricating observations, although it is evident that he should have been more careful.

But is there evidence for the omission or addition of days in the Roman calendar, and could the Roman calendar in fact be the cause of Ptolemy's errors without considering computation from Hipparchus's theory? This is what Kepler believed he found by 1622, the year after the publication of Epitome 7, as he explains in a memoir called "Against the nonuniform precession of the equinoxes" addressed to 
Emperor Ferdinand II..$^{22}$ He enlarges upon, and indeed contradicts, his speculation in the Epitome, and is now more specific (20.1.134-35).

I reasoned that Ptolemy, an inhabitant of Egypt, was deceived by the Roman calendar and by the license of the priests and impetuosity of the rulers of Egypt, who intercalated at Rome, not as heaven required, but just as they were incited (to do), this way and that, in accordance with some national superstition; indeed those (priests and rulers) entirely annulled the perfectly equal Egyptian months and introduced the Roman calendar into public use. And thus the annual calendars were not computed locally, but were sent from Rome, not the least instance of servitude. Of this not unsuitable conjecture, there was lacking only historical testimony, by which it would be confirmed, that in the year 139 after Christ or the previous year, one day had been removed out of order. But behold the very thing, unless all sound reason deserts me. For in the year 139 after Christ, Antoninus Pius II and Bruttius Praesens Consuls, Censorinus, the most scrupulous and careful reckoner of chronology, attributes the first of the Egyptian month Thoth to the twelfth day before the Kalends of August or 21 July, which observed in regular order, as elsewhere Censorinus preserves, ought to be attributed to the thirteenth day before the Kalends of August or 20 July, unless a day was removed out of order and the days of the Roman year occurred earlier.

One may not doubt that Ptolemy, since he had not given attention to what Censorinus gave attention to, that an omission (of one day) had been made out of order, believed that with the twelfth day before the Kalends of August (21 July), which day was then observed in Rome, there still coincided, as before, the second day of Thoth, which nevertheless was (because of the omission of one day) the first day of Thoth, and that it (the first day of Thoth) ought from the perpetual reckoning of years be called the thirteenth day before the Kalends or 20 July. In this way a superfluous day insinuated itself into his calculation between Hipparchus and his own age and produced a longer year and a slower motion of the Sun than are correct.

What Kepler is referring to is one of the most famous passages in ancient chronology, the pertinence of which he appears to have discovered only recently, Censorinus, De die natali 21.10: "But of these (Egyptian years), the beginnings are always taken from the first day of its month the name of which among the Egyptians is Thoth, and which in this year (238) was the seventh day before the Kalends of July (25 Jun) although one hundred years ago (139), Emperor Antoninus Pius II and Bruttius Praesens consuls at Rome, the same day was the twelfth (corr. thirteenth) day before the Kalends of August (21 July, corr. 20 July), at which time Canicula is accustomed to make its rising in Egypt." Censorinus here gives the Roman calendar date of the beginning of a Sothic Cycle, when the (nominal) heliacal rising of Sirius in Lower Egypt occurs on 1 Thoth in the Egyptian calendar, in the year of the consulship of Emperor Antoninus Pius for the second time and of Caius Bruttius Praesens, 139, which date appears as ante diem XII Kal. Aug. (21 July). This 1 Thoth was the 
beginning of Antoninus 3, the year in which Ptolemy observed both equinoxes and the summer solstice about one day late, as Kepler knows. Now, correctly 1 Thoth was on ante diem XIII Kal. Aug. (20 July), a simple enough emendation of XII to $\mathrm{XIII}$ in the text of Censorinus, which was made by Scaliger, as Kepler soon learned or perhaps already knew. But here he takes XII as the correct reading and explains that in the year 139 the priests in Rome omitted one day "out of order" (extra ordinem) so 1 Thoth occurred on XII Kal. Aug. instead of XIII Kal. Aug., which Ptolemy in Egypt had not noticed, not "given attention to" (attenderet), meaning that he did not know it. How this affects the conversion between the Roman and Egyptian calendars will be taken up after reviewing Kepler's later consideration of this subject.

For it comes up again in a letter of $8 / 18$ February 1624 to Paul Crüger as part of a description of the configuration of the heavens at Creation, which we shall also consider below. Kepler notes that the observations cited in the Almagest in the calendar of Dionysius appear three or four days early, and suggests that it was difficult for Hipparchus to convert those dates to the Egyptian calendar without error. He then continues (18.157):

But also in the case of Ptolemy, I think that the three cardinal points, two observations of Venus, and one of Mercury all correspond to the preceding days. Unless there were observations of the Moon, which do not allow a day to pass unnoticed, I believe that many of the preceding (observations) are to be placed back to earlier days on account of what Censorinus observes, that in the first (corr. third) year of Antoninus, the first day of Thoth was not on 20 July but on 21 July, from which you will gather that a displacement of the Roman year was made for the sake of superstition or flattery, as was sometime done earlier by the testimony of Dio, with a restitution made in the following year. Therefore, if this displacement was announced in Egypt and received in use there after the last observation of the Moon, since already the use of the Egyptian year was abolished, Ptolemy could be deceived.

Now Kepler does not specify whether a day had been removed from or added to the Roman calendar, only that there had been a displacement (luxatio), and the single example he cites, from Cassius Dio (48.33), of one day added and later subtracted, was around $41 \mathrm{BC}$, when intercalation was irregular, nowhere near the age of the Antonines. Crüger must have pointed out to Kepler that the text of Censorinus is in error and need only be emended from XII to XIII for the correct correspondence of the Roman and Egyptian calendars, a conclusion Crüger seems to have reached on his own. Kepler's reply, in a letter of 1 May 1626 (18.264), shows that he already knew this, but would prefer not to accept it as the alternatives are either accusing Ptolemy of fraud or proposing a long-period inequality of the Sun not supported by observation.

Joseph Scaliger warned me of the passage from Censorinus, and he, as you, identifies it as an error. ${ }^{23}$ If I could excuse Ptolemy so that I were not compelled to accuse him of fraud, I would congratulate myself. But if 
the probability of error in Censorinus will melt this buttery support for me (colloquabit mihi hoc fulcrum butyraceum), I shall have recourse to secular equations, to similar proofs (experimenta) in all the planets; in the Sun itself, which, through eclipses of the Moon, is found to progress nonuniformly with respect to the fixed stars (only) in minutes of arc, which I prove by four or five eclipses of the Moon.

The "buttery support" is the text of Censorinus, but only if XII be considered correct. And this Kepler does not give up, although he does change his interpretation of just what happened to the Roman calendar that led Ptolemy astray. His latest explanation, which may have been written before the preceding letter, is in the Rudolphine Tables, in the rule (188) for finding the day of any year on which the equinox occurs. After explaining the rule and giving a computed example for what he calls Hipparchus's vernal equinox of $147 \mathrm{BC}$, that is, $-146 \mathrm{Mar} 24-$ Ptolemy does not record that equinox although he does record Hipparchus's autumnal equinox (5) of -146 Sep 26/27 and vernal equinox (6) of -145 Mar 24-he continues (10.238):

Caution: The days of the equinoxes are not in every case shown by this rule, as for example those Ptolemy asserts were observed by himself. Consequently, in this case, however much the equinoxes differ, either in time among themselves or from the uniform precession, we should in no way be influenced by the authority of Ptolemy, who appears to have been altogether mistaken in reckoning the days of the Egyptian year, perhaps mislead either by Hipparchus's calculation of the motion of the Sun or by the calendar and the Roman intercalation. This conjecture is confirmed by one passage of Censorinus, who-in that very year (139) in which Ptolemy last observed the Moon, and after that, when an extraordinary Roman intercalation had just been announced in Egypt, observed both equinoxes-refers the first day of the first Egyptian month Thoth to the twelfth day before the Kalends of August (21 July) although it should be assigned to the thirteenth day ( $20 \mathrm{July}$ ) if the same uniformity of Julian intercalation was observed then as now and no extraordinary intercalation was revealed that year by the Priests.

But if the opinion of Ptolemy's care is higher than (allows) that he could be deluded by either calculation or the Roman year, one will have to have recourse to the desperate measure of saying that around the time of Ptolemy the equinoxes made a leap (forward in time), which they compensated in the next centuries up to the time of Proclus. And in fact, I prove from the most secure examples of observations of eclipses that the progress of the Sun with respect to the fixed stars themselves is near the least degree nonuniform. If God wills, I will publish one book on this subject.

An additional inequality in the motion of the Sun, also referred to in the letter to Crüger, must be very small, for if it were large enough to change the time of the equinox by one day, about $1^{\circ}$ in longitude, it would affect the times of lunar eclipses by about 2 hours, which is ruled out by the records of ancient eclipses, including those observed by Ptolemy. Hence the motion of the Sun is "near the least degree 
nonuniform" (circa minima inaequalem), that is, very nearly uniform. Since any additional inequality in the motion of the Sun, if present at all, is too small to affect the times of equinoxes by one day, Kepler here offers two explanations for what can now only be Ptolemy's errors. The first is that he was misled (seductus) by Hipparchus's solar theory, as he had suggested in the Epitome and as Longomontanus also said although more strongly. In fact, Kepler notes in the margin: "Longomontanus (Theor. Ast. 1.33) said that he (Ptolemy) was not only mistaken in observing, but also clearly fabricated (finxisse) the observed (equinox), which he computed from Hipparchus." The other explanation is Censorinus's correspondence of I Thoth of Antoninus 3 in the Egyptian calendar to XII Kal. Aug. (21 July) instead of the correct XIII Kal. Aug. (20 July), but he now attributes the correspondence, not to the omission of one day, but to an "extraordinary Roman intercalation" (intercalatione Romana extraordinaria), an intercalation out of order, which would appear to be an addition of one day, made by the Priests (Pontificibus) in Rome, which was then announced in Egypt. The intercalation occurred after Ptolemy's latest dated lunar observation, on 25 Phamenoth (1399 February) of the Mcon near quadrature (Almagest 5.3), since the position of the Moon in that observation corresponds to the correct date in the Egyptian calendar. The point in either case, omission or addition, is that Ptolemy did not know that there had been a displacement in the Roman calendar, which was announced in Egypt in an annual fasti, a calendar, sent from Rome, and thus made errors in converting Roman to Egyptian dates in the year Antoninus 3 in which he observed the equinoxes and solstice.

So which is it, an omission or an addition of one day? Kepler assumes, as noted, that Ptolemy dated his observations in the Roman calendar and then converted to the Egyptian calendar without knowing that a displacement had occurred in the Roman calendar. The Egyptian calendar runs continuously with no displacement. Kepler is not concerned with the different beginning of the day in each calendar, the Julian day at midnight, the Egyptian day at the following sunrise, just with a difference of one day. Figure 7 shows the effect of the conversion in three ways. The first line is the Egyptian calendar in 139 beginning with the date of Ptolemy's latest lunar observation, 25 Phamenoth of Antoninus 2, and the next date shown

25 Phamenoth Antoninus 2

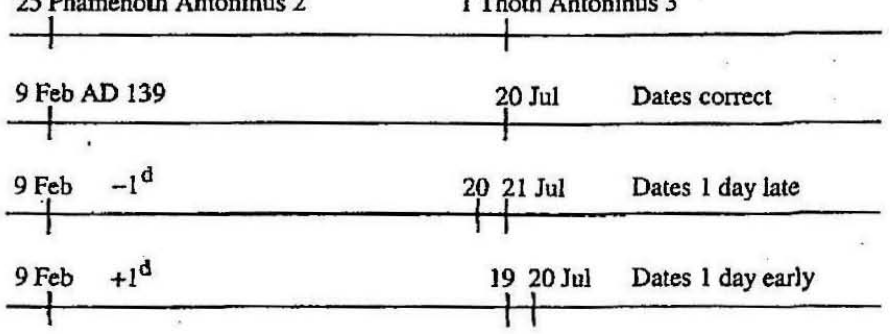

XIIII Kal. Aug. $\equiv 19 \mathrm{July} ;$ XIII Kal. Aug. $\equiv 20 \mathrm{July}$ XII Kal. Aug. $\equiv 21 \mathrm{July}$

Fig. 7 Kepler and Censorinus. Conversions of Roman to Egyptian calendar in 139 for 1 Thoth 
is 1 Thoth of Antoninus 3. The second line shows the correct corresponding dates in the Roman calendar, 9 February and 20 July (XIII Kal. Aug.); the conversion of 20 July to 1 Thoth is correct for the undisplaced Roman calendar. The third line with $-1^{d}$, as in the memoir to Ferdinand II, shows the effect of the omission of one day after 9 February, by which 20 July (XIII Kal. Aug.) occurs one day before 1 Thoth, which thus occurs on 21 July (XII Kal. Aug.), as in the text of Censorinus, and all following dates in the Egyptian calendar correspond to one day later in the Roman calendar. Hence, if Ptolemy did not know this, he would convert Roman dates to Egyptian dates one day later than the undisplaced conversion, and this would have the result of making the equinoxes and solstice observed in Antoninus 3 one day late in the Egyptian calendar. For example, the autumnal equinox (12) in 139 actually observed on VII Kal. Oct. (25 Sep) would, because of the omission of one day in the Roman calendar, be dated VI Kal. Oct. (26 Sep) and converted to 9 Athyr instead of 8 Athyr corresponding to VII Kal. Oct., thus one day late in the Egyptian calendar. ${ }^{24}$ Finally, the fourth line with $+1^{d}$ shows the effect of the "extraordinary Roman intercalation" in the Rudolphine Tables, which appears to be an addition of one day after 9 . February. Now 20 July (XII Kal. Aug.) occurs after Thoth 1, which occurs on 19 July (XIIII Kal. Aug.), so this cannot account for Censorinus's conversion of 1 Thoth to XII Kal. Aug., and the conversion of all subsequent dates from the Roman to the Egyptian calendar would be one day early, not one day late. Thus, if Ptolemy were not aware of the intercalation of one day, his conversion of the dates of the equinoxes and solstice in Antoninus 3 from the Roman to the Egyptian calendar would be one day early, which is clearly not so as they are all late. The equinox observed on VII Kal. Oct. ( $25 \mathrm{Sep}$ ) would, because of the addition of one day, be dated VIII Kal. Oct. (24 Sep) and converted to 7 Athyr instead of 8 Athyr, which did not happen as the equinox is dated 9 Athyr. Hence, Kepler's explanation in the earlier memoir of an omission of one day can, in principle, explain the late dates of the equinoxes and solstice in the Almagest, but the addition of one day in the Rudolphine Tables cannot. Why he should have changed his mind about this I do not know, and it does not seem likely that by "extraordinary Roman intercalation" he still means an omission; but I can say from the effort of working it out and explaining it that, as simple as it appears, it can be confusing, and it is easy to think that adding one day to the Roman calendar will advance the date in the Egyptian calendar by one day.

Without invoking an extraordinary omission or addition of a day, it might be suggested that there was a systematic error of one day in the conversion between the Roman and Egyptian calendars for Antoninus 3, and perhaps other years, common to Censorinus and Ptolemy, as unlikely and inexplicable as that might appear, especially since they lived a hundred years apart. But even then there would be the problem that the autumnal equinox (11) of 25 September 132, used to establish the Sun's epoch (Almagest 3.7), which correctly occurred on 24 September and is thus also one day late, is several years before, not only the presumed extraordinary omission or addition of a day, but also five correctly dated observations of the Moon, including three eclipses. Thus, any error would have to occur intermittently. And the very idea that Ptolemy would date observations in the Roman calendar in Alexandria, which had its own Alexandrian calendar, is hardly possible. ${ }^{25}$ So as 
clever as Kepler's explanation may be, and it is clever, it cannot be correct. Still, he has no doubt that Ptolemy's equinoxes are late by one day, and he later says (10.242) that all of Ptolemy's longitudes of planets are reduced by about $-1 ; 3^{\circ}$, which is very nearly correct since the error in the mean longitude of the Sun at the autumnal equinox (11) of 25 September 132 is $-1 ; 5^{\circ}$.

Kepler had a yet more ambitious reason for correcting Ptolemy's equinoxes than finding a correct and consistent solar theory. From the time of the Mysterium Cosmographicum (1596), and doubtless before that, he reasoned that God would not create the world with the various bodies in arbitrary positions, but must have chosen some rational initial configuration. He set out such a configuration in the Mysterium (23) for 27 April $3978 \mathrm{BC}$, but later changed his mind, and in a note in the 1621 edition gives the date 24 July 3993 BC, with the Sun and Moon at the beginning of Cancer near Regulus and the planets in the direction of solstices or equinoxes. After finding that Longomontanus had done something similar in Astronomia Danica, the Sun at apogee at the autumnal equinox in $3967 \mathrm{BC}$, he gives more details in the letter to Paul Crüger of $8 / 18$ February 1624 , without the date, but with the locations near or at the solstices and equinoxes, together with a diagram in which the locations are heliocentric (18.155-57). As we saw earlier, he notes possible errors in the conversion of dates from the Dionysian to the Egyptian calendar in ancient observations cited by Ptolemy and errors in Ptolemy's observations of equinoxes and the solstice, two observations of Mercury and one of Venus, and to explain them refers to the displacement in the Roman calendar shown by Censorinus's conversion of 1 Thoth. This shows clearly that Kepler's investigation of errors in Ptolemy's observations is related to the configuration of the heavens at Creation and thus to the date of Creation. The locations at Creation, that is, the evening of the second day (feria secunda, Monday) in Chaldea, when God created the firmament, 24 July 3993 $\mathrm{BC}$ at 0;33,26 hours after noon at Uraniborg, are finally set out in the Rudolphine Tables. As examples of summing mean motions, he computes the mean heliocentric longitude of each planet, the longitude of its aphelion and ascending node, and the equivalent geocentric longitudes of the Sun and Moon (10.121-23), which he then places in the tables of epochs. And for each, he asks "What if?" (Quid si), and gives the locations exactly at the equinoxes and solstices according to God's plan. The computed and intended locations are as follows:

\begin{tabular}{|c|c|c|c|c|c|c|c|c|c|}
\hline \multirow[b]{2}{*}{ Planet } & \multicolumn{6}{|c|}{ Computed } & \multicolumn{3}{|c|}{ What if? (Quid si) } \\
\hline & & $\bar{\lambda}$ & & $\lambda_{\mathrm{A}}$ & & $\delta$ & $\vec{\lambda}$ & $\lambda_{\mathrm{A}}$ & $\delta$ \\
\hline Saturn & $\Omega$ & $5 ; 29,57^{\circ}$ & l & $28 ; 24,6^{\circ}$ & $r$ & $0^{\circ}$ & $\Omega 0^{\circ}$ & $\bumpeq 0^{\circ}$ & $\gamma 0^{\circ}$ \\
\hline Jupiter & $\eta_{0}$ & $7 ; 3,21$ & $\sigma$ & $23 ; 34,18$ & $\sigma$ & 0 & 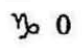 & б 0 & $\sigma_{0} 0$ \\
\hline Mars & $\sqrt{0}$ & $10 ; 43,52$ & $\gamma$ & 15 & t & 15 & б 0 & భ/ब 0 & $\Upsilon 0$ \\
\hline Sun (Earth) & $\sigma$ & 0 & $\gamma$ & $0 ; 0,1$ & & - & $\sigma 0$ & $\gamma 0$ & - \\
\hline Venus & б & 0 & $\Omega$ & 0 & $r$ & 0 & $\sigma 0$ & $\Omega 0$ & $r 0$ \\
\hline Mercury & $r$ & $0 ; 0,1$ & $\sigma$ & 0 & $\eta_{0}$ & 0 & $\uparrow 0$ & $\sigma 0$ & no 0 \\
\hline Moon & II & $22 ; 57,2$ & $\underline{\Omega}$ & 0 & $\sigma$ & $0 ; 0,1$ & $\sigma 0$ & $\Omega 0$ & б 0 \\
\hline
\end{tabular}


What Kepler wishes to find is the mean longitude of every body and the longitude of aphelia (apogees for Sun and Moon) and nodes at an equinox or solstice at some date close to Creation according to scriptural chronology. Since there are four possible locations, all mean longitudes near, if not exactly at, equinoxes and solstices must occur periodically, and over a period of thousands of years very small changes in mean motion in longitude can place each body exactly where required. But the aphelia and nodes move so slowly that these locations occur very infrequently, although a surprisingly large number of the computed positions are already at them. Presumably the exact date and time are determined by the Sun at the summer solstice, Cancer $0^{\circ}$; by remarkable luck, Venus at Cancer $0^{\circ}$ and Mercury within $1^{\prime \prime}$ of Aries $0^{\circ}$ would seem to determine the year (in fact these are in error by several degrees). The time required for the Moon to move to Cancer $0^{\circ}$ is half a day, Mars was at Cancer $0^{\circ} 20$ days, Jupiter at Capricorn $0^{\circ} 85$ days, and Saturn at Libra $0^{\circ} 164$ days earlier, so these could easily be adjusted over so long a period. But Jupiter's aphelion was at Cancer $0^{\circ}$, if ever, 1800 years earlier, and Saturn's aphelion will not be at Libra $0^{\circ}$ for 1500 years. Since the aphelion of Mars is at Taurus $15^{\circ}$, it is uncertain whether it should be at Aries $0^{\circ}$ or Cancer $0^{\circ}$; one way or the other, the motion would take 2400 years. (That the nodes are, except for Mars, at the required locations is the result of errors in their motions in the tables. For Saturn and Mercury the differences are over $60^{\circ}$, although Mars happens to be close to Aries $0^{\circ}$.)

It is here that an investigation of Ptolemy's observations is essential because errors of, in fact, many degrees in the longitudes of apsides and nodes found by Ptolemy when corrected could bring these where they belong at the date of Creation, or so Kepler could hope. And this investigation he intends to take up, for after the examples of computing the positions at Creation, he remarks (10.123): "Concerning this situation and disposition of the initial positions from which all the motions come forth, there is a large subject for philosophizing, if the proposed material is accessible. But this speculation is to be deferred until another treatise where the reasons and foundations will be set out from which the positions at the time of Ptolemy have been brought to light." Kepler is here referring to two works. The first may be one, not completed but surviving among Kepler's manuscripts, known as the "Examination of the Observations of Regiomontanus and Walther," which also considers ancient observations reported by Ptolemy, with the object of finding secular equations such that, perhaps, the bodies all could be at their required positions at Creation. ${ }^{26}$ The second is a separate treatise on the positions at the time of Ptolemy, perhaps also on Ptolemy's observations in general with an analysis of the errors and their causes and any applicable secular equations. This would have been of interest, and with more detail than he had offered thus far. But it does not appear that the treatise was ever written, although notes in Kepler's manuscripts may have been intended or useful for it. So it is evident that, just as for Tycho and Longomontanus, Ptolemy's observations were of serious concern, presenting problems that had not been solved. And the literature of the last two hundred years shows that they are still subject to discussion and speculation, much of it merely repeating what was already written long ago, although not nearly so interesting or ingenious. 


\section{Appendix: Equinoxes and Solstices in the Almagest}

Ptolemy cites twelve equinoxes and two solstices with specific dates and times and several others with implied dates. For those with dates and times, here numbered in chronological order, we give the observer, year, date, and time in the Almagest along with the date and apparent time by modern computation, the difference in time $\Delta t$, cited time minus computed time, and for the cited time the differences in declination $\Delta \delta$ and longitude $\Delta \lambda$ from the declination and longitude at the computed time. Thus, $\Delta t, \Delta \delta$, and $\Delta \lambda$ are the errors in time, declination, and longitude at the cited times. Ptolemy's times of earlier observations are approximate, midnight, dawn, noon, sunset, evening, but he interprets them as occurring at quarter days, even for the solstice of Meton at dawn, which we give here as 0,6,12, and 18 hours. Since the cited times are approximate, the errors are also approximate. The computations, of apparent (not mean) local time for the meridians of Athens (1), Rhodes (2-10), and Alexandria (11-14), are geocentric, may have an uncertainty of a few minutes, and small inequalities cause the intervals between equinoxes and the tropical year to vary slightly from year to year. Reduced to the meridian of Alexandria, (1) is $+0 ; 25^{\mathrm{h}}$ and $(2-10)+0 ; 7^{\mathrm{h}}$ later. We have used the Alcyone Ephemeris for these calculations.

$\begin{array}{rrrrrrlrrrc}\text { No. } & \lambda & \text { Obs. } & \text { Year } & \text { Date } & \text { Time } & \text { Mod. Date } & \text { Tine } & \Delta t & \Delta \delta & \Delta \lambda \\ 1 & \text { Can 0 } & \text { Met. } & -431 & 27 \text { Jun } & 6^{\text {h }} & 28 \mathrm{Jun} & 10 ; 29^{\mathrm{h}} & -28 ; 29^{\mathrm{h}} & -0 ; 0,18^{\mathrm{c}} & -1 ; 8^{\mathrm{c}} \\ 2 & \text { Lib 0 } & \text { Hip. } & -161 & 27 \mathrm{Sep} & 18 & 27 \mathrm{Sep} & 2 ; 29 & +15 ; 31 & -0 ; 15,36 & +0 ; 38,49 \\ 3 & \text { Lib 0 } & \text { Hip. } & -158 & 27 \mathrm{Sep} & 6 & 26 \mathrm{Sep} & 19 ; 57 & +10 ; 3 & -0 ; 10,7 & +0 ; 25,8 \\ 4 & \text { Lib 0 } & \text { Hip. } & -157 & 27 \mathrm{Sep} & 6 & 27 \mathrm{Sep} & 1 ; 43 & +4 ; 17 & -0 ; 4,19 & +0 ; 10,41 \\ 5 & \text { Lib 0 } & \text { Hip. } & -146 & 27 \mathrm{Sep} & 0 & 26 \mathrm{Sep} & 17 ; 49 & +6 ; 4 & -0 ; 6,13 & +0 ; 15,26 \\ 6 & \text { Ari 0 } & \text { Hip. } & -145 & 24 \mathrm{Mar} & 6 & 24 \mathrm{Mar} & 15 ; 1 & -9 ; 1 & -0 ; 8,47 & -0 ; 21,52 \\ 7 & \text { Lib 0 } & \text { Hip. } & -145 & 27 \mathrm{Sep} & 6 & 26 \mathrm{Sep} & 23 ; 41 & +6 ; 19 & -0 ; 6,21 & +0 ; 15,46 \\ 8 & \text { Lib 0 } & \text { Hip. } & -142 & 26 \mathrm{Sep} & 18 & 26 \mathrm{Sep} & 17 ; 9 & +0 ; 51 & -0 ; 0,51 & +0 ; 2,7 \\ 9 & \text { Ari 0 } & \text { Hip. } & -134 & 24 \mathrm{Mar} & 0 & 24 \mathrm{Mar} & 6 ; 59 & -7 ; 6 & -0 ; 6,50 & -0 ; 16,58 \\ 10 & \text { Ari 0 } & \text { Hip. } & -127 & 23 \mathrm{Mar} & 18 & 23 \mathrm{Mar} & 23 ; 23 & -5 ; 23 & -0 ; 5,15 & -0 ; 13,5 \\ 11 & \text { Lib 0 } & \text { Ptol. } & 132 & 25 \mathrm{Sep} & 14 & 24 \mathrm{Sep} & 4 ; 58 & +33 ; 2 & -0 ; 33,6 & +1 ; 22,25 \\ 12 & \text { Lib 0 } & \text { Ptol. } & 139 & 26 \mathrm{Sep} & 7 & 24 \mathrm{Sep} & 21 ; 44 & +33 ; 16 & -0 ; 33,18 & +1 ; 22,55 \\ 13 & \text { Ari 0 } & \text { Ptol. } & 140 & 22 \mathrm{Mar} & 13 & 21 \mathrm{Mar} & 16 ; 15 & +20 ; 45 & +0 ; 20,18 & +0 ; 50,31 \\ \text { 14 } & \text { Can 0 } & \text { Ptol. } & 140 & 25 \mathrm{Jun} & 2 & 23 \mathrm{Jun} & 14 ; 9 & +35 ; 51 & -0 ; 0,28 & +1 ; 25,31\end{array}$

Observations (2-4) were perhaps only reported by Hipparchus and not made by him at Rhodes. The time of ( 8 ), with its very small $\Delta t$, is given as "evening," which could be later than $18^{\mathrm{h}}$, but before $0^{\mathrm{h}}$ at which $\Delta t=+6 ; 51^{\mathrm{h}}$. The negative $\Delta \delta$ in (2-10) implies that the equator was set too low, in most by about $6^{\prime} \pm 2^{\prime}$, and, aside from (2-3), are consistent enough to show that they must be from interpolation between measurements of meridian altitude, and not observed with an equatorial ring close to the horizon where refraction would produce a larger range or even positive values of $\Delta \delta$. Using meridian altitudes, refraction would change the times of the equinoxes by less than $\pm 0 ; 45^{\mathrm{h}}$, a small fraction of $\Delta t$. Ptolemy's observations were probably of meridian altitudes even though $\Delta t$ is so large, since he criticizes the use 
of rings. Longomontanus assumes that both Hipparchus and Ptolemy observed with a ring, and attempts to correct for refraction the times of equinoxes believed to be observed close to the horizon. In fact, (6) was also observed in Alexandria with an equatorial ring, which showed the time about 5 hours later, at $11^{\mathrm{h}}$, reducing $\Delta t$ to $-4 ; 1^{\mathrm{h}}, \Delta \delta$ to $-0 ; 3,55^{\circ}$, and $\Delta \lambda$ to $-0 ; 9,44^{\circ}$.

\section{Notes}

1. This is the way Battān $\overline{1}$ was understood in Europe, by the writers we are considering, but in Chapter 52 he suggests, and appears to favor, a variable precession and tropical year although he proposes no model or parameters. There is a detailed study of this subject by Ragep (1996) and further reference in his paper in this volume.

2. In the section on each, references in parentheses are to volume and page numbers in: Brahe (1913-1929), Longomontanus (1622), and Kepler (1937- and 1858-1871). Full descriptions of these are in the bibliography.

3. The text reads Capricorn $5^{\circ}$. There is another ertor here as by Copernicus's tables in 1580 the eccentricity is about 0.03214 or $1 ; 55,42$, less than $2 ; 5$ by $0 ; 9,18$, and is never less than 0.0321 or $1 ; 55,34$; but the longitude of the apogee is $98 ; 42^{\circ}$, about $3 \frac{2}{3}^{\circ}$ to the east of Cancer $5^{\circ}$, and the Prutenic Tables are nearly the same.

4. How did Tycho find $\pi=28 ; 5 \frac{1}{2}^{\circ}$ ? From his star catalogue, for the end of 1600 the longitude of Spica is $198 ; 16^{\circ}$, and from the table of precession, for $12 \operatorname{Sep} 1588 \Delta \pi=-0 ; 10,28^{\mathrm{C}}$, so the longitude of Spica is $198 ; 5,32^{\circ}$. Then, taking Ptolemy's interval from Spica to $\gamma$ Arietis, $-170 ; 0^{\circ}$, the longitude of $\gamma$ Arietis and the precession $\pi=198 ; 5,32^{\circ}-170 ; 0^{\circ}=28 ; 5,32^{\circ} \approx$ $28 ; 5,30^{\circ}$. Tycho explains that from his own interval from Spica to $\gamma$ Arietis, $-170 ; 39^{\circ}, \pi=$ $27 ; 26^{\circ}$ (strictly $27 ; 26,32^{\circ}$ ), but since the fixed stars do not move in relation to each other, it does not matter which interval he applies to find the difference of precession as long as he applies it at both equinoxes, and Ptolemy's interval from Spica is consistent with the interval from Regulus. This is correct since what Tycho finds is $\Delta \bar{\lambda}_{\mathrm{s}}^{*}=\Delta \bar{\lambda}_{\mathrm{s}}-\Delta \pi$.

5. Copernicus's longitude of Spica in 1515 is $197 ; 14^{\circ}$-in fact, computed from his precession theory and altered from his original computation of $197 ; 10^{\circ}$-and Tycho's $197 ; 3,30^{\circ}$ is his recomputation based upon the corrected latitude of Frauenburg (2.223). In 1586 he corrected Copernicus's 1525 longitude of $197 ; 21^{\circ}$ in the same way to $197 ; 13,55^{\circ}(10.125$, text by error 53 for $13 ; 2.223$ has $197 ; 14^{\circ}$ ), and paired it with his own longitude of $198 ; 4,24^{\circ}$ for 1586 , from which $\pi=\Delta \lambda / \Delta t=0 ; 50,29^{\circ} / 61^{y}=0 ; 0,49,39^{\circ / y}$ or $1^{\circ}$ in about $72 \frac{1}{2}$ years. By modern computation, the longitude of Spica in 1515 is $197 ; 5^{\circ}$ and in $1525197 ; 14^{\circ}$, close enough to Tycho's corrections.

6. This is correct, for in the late sixteenth century by Copernicus's theory the rate of precession is about $36^{\prime \prime}$ per year and the tropical year $365 ; 14,48^{d}$, the same as Ptolemy found, very nearly the slowest precession and longest year, while Tycho found $51^{\prime \prime}$ per year, faster by $15^{\prime \prime}$, and $365 ; 14,31,52,30^{d}$, shorter by $0 ; 6,27^{\text {h }}$, which refutes Copernicus's theory. However, Tycho does note that Copernicus's mean precession of $0 ; 0,50,12,5^{\circ / y}$ differs from his by only $-0 ; 0,0,48^{\circ}$.

7. This is the year of Jālāl ad-Din Malik Shāh of 1079, which Scaliger earlier favored and had

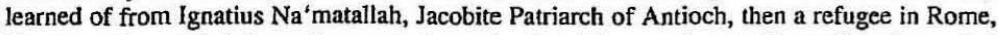
his source for much information on eastern calendars. The year is stated in various forms, but Scaliger gives it as $365^{\mathrm{d}} 5^{\mathrm{h}} 880^{\mathrm{ch}}$, where 1 hour $=1080$ chalakim, a division of the hour in the Hebrew calendar; the tropical year is thus $365^{d} 5 ; 48,53,20^{\text {h }}$, in fact superior to the Alfonsine and differing from Tycho's by $+0 ; 0,8,20^{\mathrm{h}}$.

8. Cited by Grafton $(1993,201)$, from De emendatione temporum $(1583,128)$. 
9. Cynosura, literally "dog's tail," is a name for Ursa Minor, used notably by Aratus. Copernicus also uses it in his star catalogue. That Hipparchus's found Polaris $12 ; 24^{\circ}$ from the pole is cited by Ptolemy from Marinus in Geography 1.7.4. Since it was then the most distant of the stars in Ursa Minor in declination from the pole, it is called the "southernmost," which Scaliger later criticizes as an error because he believes the pole of the world is always at or near Polaris. Grafton $(1993,487)$, notes that "southern" was sometimes emended to "northern" in translations of the Geography since by the sixteenth century Polaris had become the northernmost star. He also notes (464) that in the second edition of De emendatione temporum, Scaliger gives the least distance as $3 ; 24^{\circ}$ and concludes that the pole of the equator has approached the pole star by about $9^{\circ}$. The present distance of less than $3^{\circ}$ he perhaps received from Tycho, who also mentions it in his letter below.

10. It appears from examples for Regulus and $\eta$ Gem that he was computing true risings, when the Sun and star cross the horizon at the same time, rather than apparent risings, which are more difficult and uncertain to compute. Nevertheless, his conclusion is correct, for by modern computation at 100-year intervals, the apparent heliacal rising of Sirius in Alexandria for -1800 to 900 is on 20 July and 1000 to 1600 on 21 July (Julian), although different methods of computation can differ slightly. Scaliger refers to acronychal risings, although perhaps not explicitly for Sirius, but these are not as constant, for -1800 to 1600 advancing from 25 December to 1 January. Tycho's statement that after about 500 years Polaris will be $27 \frac{1}{2}^{\prime}$ from the pole is very accurate, for its minimum distance (without nutation), will be $0 ; 27,15^{\circ}$ in $2102-03$.

11. Scaliger's objections to the precession, including in the Diatribe, are treated by Grafton (1993, 459-488). The Diatribe was already much criticized in its day; a detailed analysis and very sharp criticism by Kepler is published by Frisch (Kepler 1858-1871, 8.273-93).

12. The Greek text has $365 \frac{1}{4}+\frac{1}{76}$ days, but the fraction $\frac{1}{76}$ seems to be omitted in earlier paraphrases of this passage and accounts of the Metonic cycle. It was commonly thought that the cycle was 19 Julian years of $365 \frac{1}{4}$ days, $6939 \frac{3}{4}$ days, as in the ecclesiastical calendar, rather than Meton's 6940 days. It should be noted that a luni-solar calendrical cycle as applied to months must be an integral number of days since new Moons appear only in the evening separated by (nearly) integral days.

13. Longomontanus's explanation was later proposed, surely independently, by Tobias Meyer in a letter to Euler. Of course, neither knew the Babylonian origin of Hipparchus's mean synodic month. There is a rather detailed discussion of Hipparchus's tropical year and precession by Swerdlow (1980).

14. Holger Rosenkrantz (1574-1642), a friend and correspondent of Tycho's, was married to Tycho's niece, supported Tycho's claims in Denmark after he had left Hven, and doubtless knew Longomontanus well. The correspondence is published in Dreyer's edition and there is a biography by Christianson $(2000,344-346)$. He assembled a great library and was particularly concerned with theology, although sufficiently unorthodox and fanatical to be charged with heresy in his later years.

15. For -3963 Jan 1 noon, $\bar{\lambda}_{s}=248 ; 33,54^{\circ}$, for -3966 Jan 1 noon, $\bar{\lambda}_{s}=248 ; 17,45^{\circ}$. Since the equinoxes were then in the apsidal line where the equations are zero, the difference in longitude to the following vernal equinox is $111 ; 42,15^{\circ}$ and to the autumnal equinox $291 ; 42,15^{\circ}$, for which the difference in time is $291 ; 42,15^{\mathrm{c}} / 0 ; 59,8,19,45^{-/ 4}=295^{\mathrm{d}} 22 ; 50,50^{\mathrm{h}}$, that is, 23 Oct at $22 ; 50,50^{\mathrm{h}}$ from noon or 24 Oct at about 11 AM Curiously, if one takes the true longitude for -3966 Jan 1 noon, $\lambda_{s}=248 ; 17,45^{\circ}+1 ; 55,32^{\circ}=250 ; 13,17^{\circ}$, the difference in longitude to the autumnal equinox is $289 ; 46,43^{\circ}$. If one then uses the mean motion of the Sun, the difference in time is $293^{\mathrm{d}} 23 ; 57,39^{\mathrm{h}}$, that is, 21 Oct at $23 ; 57,39^{\mathrm{h}}$ from noon or 22 Oct at about noon. This is not strictly correct, but the result would be that God created the world at about noon in Copenhagen.

16. Pole $E$ is described as "in the surface of the globe of the Earth," but that must be only a geometrical direction as it makes no sense to give the motion of $E$ to the Earth, and Moesgaard is surely correct in describing it as the pole of the true orbit of the Sun around the Earth, that is, of the true ecliptic itself. And the motion in the small circle produces only a motion of each point of the true ecliptic, as the true vernal equinox, in a small circle centered on the mean ecliptic, 
unlike Kepler's model, described later, which produces a rotation of the entire true ecliptic with respect to the mean ecliptic. Moesgaard also notes inconsistencies in Longomontanus's table of the inequality of precession and suggests that the table was computed for an earlier model in which the inequality of precession and variation of obliquity were produced by motions of the pole of the Earth, thus of the equator with no motion of the ecliptic, as in Copernicus's model. The model does seem inconsistent, or hard to follow, and my description is only of what is supposed to result from it.

17. There is a recent study by Buchwald $(2006,635-643)$ of this procedure applied to Tycho's observations along with other early methods of refining measurements or computations.

18. The text, three hours, is incorrect since at the equinoxes $\mathrm{I}^{\mathrm{h}}$ of time corresponds to $\mathrm{I}^{\prime}$ of declination. If the maximum equation is reduced by $20^{\prime}$, then with Ptolemy's apogee, the reduction at equinox is $20^{\prime} \sin 65 ; 30^{\circ} \approx 18^{\prime}$ of longitude, corresponding to $0 ; 24 \cdot 18^{\prime} \approx 7^{\prime}$ of declination and seven hours of time. Kepler must have computed $0 ; 24 \cdot 20^{\prime}=8^{\prime}$ of declination and thus eight hours of time, which would apply at $90^{\circ}$ from apogee, not at the equinoxes.

19. By modern computation, the closest approach of Mars to $\beta$ Sco was under $37^{\prime}$ on 19 Jan $2^{\text {h }}$ and to $v$ Sco over $2^{\prime}$ on 16 Jan $15^{\text {h }}$, which is much closer. There could be an error in converting the date from the Dionysian to the Egyptian calendar, but there was no occultation of either star and nothing even close at dawn in Alexandria on any nearby date. An occultation of Mars by the Moon approaching first quarter was visible in Athens the evening of -3564 May-from about $20^{\mathrm{h}}$ to $21 ; 15^{\mathrm{h}}$ apparent time although the exact time varies by a few minutes depending upon the value of the secular acceleration-as Kepler surely determined correctly, and "April" must be only a transcription error since on 4 April the Moon was about $20^{\circ}$ from Mars, which he could not have missed. In manuscript notes on the occultation (Kepler 1937-, 20.2.497-505), with 25 computations of the Sun, Moon, and Mars dated to the Foundation of Rome, AUC $380-431$, the one for -356 is a fragment for AUC 395 (504-505), April completed, hence May, plus day 5 , but the occultation is not noted there.

20. Here we consider the theory only geometrically; there is an explanation of the underlying physical theory of latitude by Stephenson $(1987,130-137)$, which we have found very helpful.

21. First published by Frisch (Kepler 1858-1871, 6.101-09) and more completely by Bialas (Kepler 1937-,21.1.314-29), who dates the notes to ca. 1616 and December 1621. The parameters for the variation of obliquity in the Epitome and Rudolphine Tables are found in the latter part of the notes. There are related notes published by Frisch (Kepler 1858-1871, 6.78-87, 593-596) and Bialas (Kepler 1937-, 20.1.115-33), from both before and after the publication of Epitome 7. Placing the equinoxes and solstices at eight degrees of their signs is Babylonian and found in a number of Greek sources. That Hercules did it first is more surprising.

22. First published by Frisch (Kepler 1858-1871, 6.87-89) and then by Bialas (Kepler 1937-, 20.1.134-36), who provides the date 1622 .

23. Loci ex Censorino admonuit me Jos. Scaliger, agnoscitque pro sphalmate, ut tu; 'admonuit me' also means 'reminded me' or 'advised me'. A. Grafton, in considering the passage, believes it refers only to Kepler's seeing the correction in De emendatione temporum, not to a personal communication from Scaliger since there is no evidence that Scaliger ever wrote to Kepler following Kepler's letter of May/June 1605, and Scaliger died in 1609, seventeen years before this letter to Crüger.

24. In fact, equinox (12) occurred on 24 Sep at about $22^{\text {h }}$, earlier than the recorded 26 Sep $13^{\text {h }}$ by $1^{\mathrm{d}} 9^{\mathrm{h}}$, as in the Appendix.

25. The Alexandrian calendar, introduced under Augustus in -24 , uses Egyptian month names and equal months of thirty days numbered consecutively forward, with five epagomenal days in common years and a sixth in a leap year. Ptolemy uses it in the Phases of the Fixed Stars, and nowhere does he give a date in the Roman calendar, even when citing observations made in Rome by Menelaus. In 139, 1 Thoth of Antoninus 3 in the Egyptian calendar corresponds to 26 Epiphi of Antoninus 2, or Augustus 168, in the Alexandrian calendar.

26. First published by Frisch (Kepler 1858-1871, 6.725-74) and more recently by Bialas (Kepler $1937-, 20.1 .395-455)$. This work is also referred to in the preface to the Rudolphine Tables (10.44). 